\begin{tabular}{|c|c|c|c|c|c|}
\hline MUNIBE Antropologia-Arkeologia & $n^{\circ} 67$ & $127-149$ & DONOSTIA & 2016 & ISSN 1132-2217 • eISSN 2172-4555 \\
\hline
\end{tabular}

\title{
El signum equitum de Altikogaña y el santuario del Balcón de Lazkua (Eraul, Navarra): simbología y religión de un poblado protohistórico
}

\author{
The signum equitum of Altikogaña and the sanctuary of Balcón de Lazkua \\ (Eraul, Navarra): symbolism and religion of a protohistoric village
}

PALABRAS CLAVES: Edad del Hierro, ideología, rito, lugares de culto. GAKO-HITZAK: Burdin Aroa, ideologia, erritoa, kultu-tokiak.

KEY WORDS: Iron Age, ideology, rite, cult places.

\section{Antxoka MARTínEZ VELASCO(1) \& Pedro ARGANDOÑA OTXANDORENA(2)}

\section{RESUMEN}

Las Peñas de Larrión, entre los valles de Allín y Yerri (Navarra), albergan uno de los más variados conjuntos arqueológicos de Navarra, con un abanico cronológico que se extiende desde la Prehistoria hasta las Guerras Carlistas. Destaca entre ellos por su importancia histórica y los materiales allí hallados el poblado fortificado de Altikogaña, ocupado durante toda la II. Edad del Hierro y con un final trágico tras su asalto y destrucción por parte de tropas romanas. En este trabajo se da a conocer un nuevo signum equitum procedente de Altikogaña así como el santuario de la Peña de Lazkua, que forma un conjunto con Altikogaña y completa el panorama de la Protohistoria en estas peñas.

\section{LABURPENA}

Larrioneko Haitzek, Allin eta Deierriko aranen artean (Nafarroa), Nafarroako multzo arkeologikorik aberatsenetakoa gordetzen dute bere baitan. Bertan dauden aztarnategiak Historiaurretik Karlistaldietara zabaltzen dira. Guztien artean nabarmentzen da, bertan topatutako materialei esker, Altikogañako herrixka gotortua. II. Burdin Aroan zehar okupatuta egon zen eta zorigaiztoko bukaera izan zuen erromatar tropek asaltatu eta suntsitu zutenean. Lan honetan ezagutzera ematen da Altikogañan topatutako signum equitum berria, baita Lazkuako Haitzetako santutegia, Altikogañarekin batera multzo bat osatzen duena eta aldi berean haitz horietako Protohistoriaren ikuspegia osatzen duena.

\section{ABSTRACT}

Larrion Crags, between the valleys of Allin and Yerri (Navarra), they are home to one of the most varied archaeological ensembles of Navarra, with a chronological range, which extends from prehistory to the Carlist Wars. Among all of them stands the fortified village of Altikogaña because of its historical importance and the archaeological finds from there. It was occupy during all of the second Iron Age, and had a tragic ending after his assault and destruction by Roman troops. In this paper presented a new signum equitum from Altikogaña as well as the sanctuary of the Lazkua Crag. This sanctuary forms an ensemble with Altikogaña and completes the panorama of Protohistory in these crags.

The signum equitum is a small object of bronze with shows a scheme composed by two front halves of horse competing, with a schematic design, united by the body. Base of the object is heading but it is possible to have any system that would facilitate their foot holder. Used figures and the symbolism that holds can be in relation to different signa equitum of the celtiberian area, the Valley of the Ebro or the Historical Cantabria. It has a parallel in one of the ancient finds from the oppidum of Monte Bernorio (Villaren de Valdivia, Prov. Palencia. Spain) and with it forms a typological group with their own characteristics.

The function of this object, as hypothesis, is that it was use as a scepter due to his small size. The symbolism used, the insignificant size and the finish of the piece, leads us to give a ritual or religious meaning related to rites of passage.

Next to the village of Altikogana is the Lazkua crag, at the foot of it there is a natural viewpoint hung on the wall, which it is know as the balcony of Lazkua. At the beginning of it, at the edge of the balcony, there is a set of engravings of fusiform type. It allows us to identify the place as a nemeton, a sanctuary in the open air, a place where a deity resides or manifests it and where it is possible to communicate with it. The close proximity to the town of Altikogana is what allows associating both.

The identification of the sanctuary and its relationship to a particular town, are repeat in Murillo (Mues). Both are two new identifications in Navarra, and they are coherent with other sanctuaries of the Iberian Peninsula. All this, with the identification of a new signum equitum, allows opening new ways to the study of symbols and religion of the Iron Age.

\footnotetext{
(1) Historiaurreko Arkeologia Saila, Aranzadi Zientzi Elkartea. Donostia-San Sebastian. antxokagaldakao@hotmail.com

(2) Eusko lkaskuntza.
} 


\section{1.- INTRODUCCIÓN}

No hay uniformidad en la zona para denominar a las diferentes peñas calizas que separan los valles de Allín y Yerri, al oeste de Estella, en Navarra. En los pueblos de Allín no las individualizan y se conocen como Peñas de Larrión, aplicándoles el nombre del pueblo que está a sus pies y al que pertenece su parte orientada al oeste en forma de farallón rocoso (fig. 1).
En Larrión las conocen con los nombres de Peña Grande, la de Medio y la de los Gitanos. Son los habitantes de Eraul, que históricamente han explotado de forma privativa las laderas orientales de las peñas, quienes las han individualizado con los topónimos de Lazkua, Altikogaña y Bargagorria, según su posición escalonada de norte a sur y en orden descendente de cota, y que son los nombres más utilizados en la actual forma normalizada de la toponimia menor (JIMENO, 1995: 119, 120 y 125) (fig.

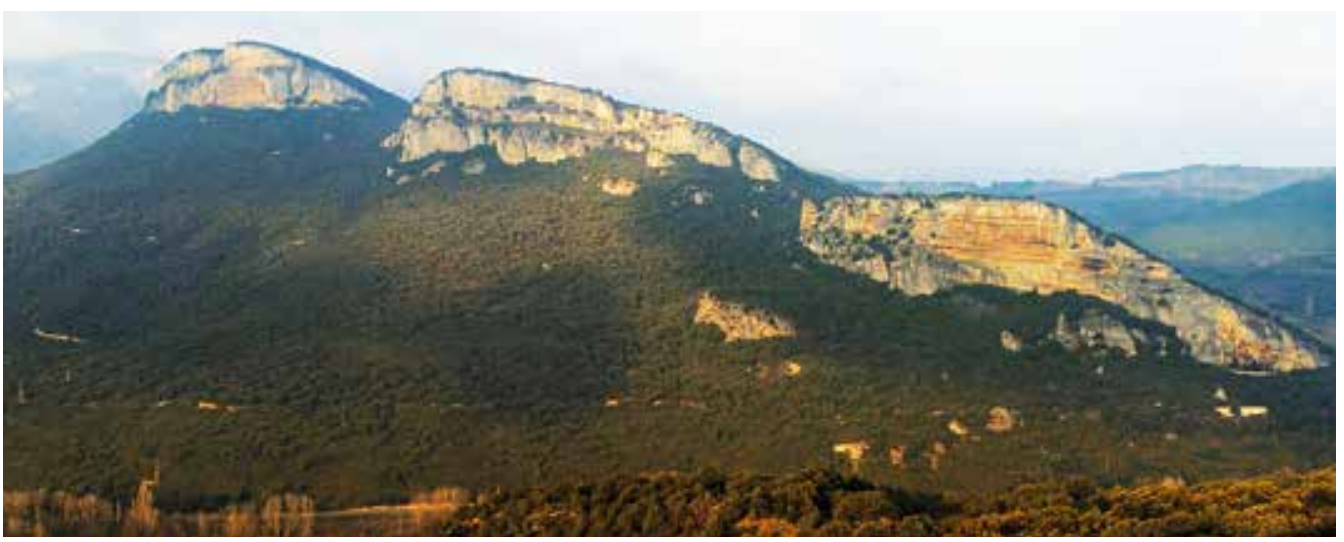

Fig. 1. Vista general de las Peñas de Larrión (Navarra). De izquierda a derecha: Lazkua, Altikogaña y Bargagorria / Overview of crags of Larrion (Navarra). From left to right: Lazkua, Altikogaña and Bargagorria (Photo: P. Argandoña 2014).

2). Tanto los habitantes de Allín como los de Yerri son coincidentes en denominar Peñas de San Fausto a las que constriñen el paso del río Urederra y conforman, por su orilla izquierda, el desfiladero que dificulta el acceso al valle por su entrada natural. En la otra margen del río, es la ladera del monte Belastegi la que baja abruptamente hasta el cauce con otros cortados de menos fuste, en el paraje de Eulz (Allín) llamado Arrunbia (de arrobi=cantera).

Estas tres peñas albergan sendos yacimientos que se han ido revelando como uno de los conjuntos más interesantes de la Protohistoria navarra. En la peña de Lazkua, la más septentrional, se conocen varios abrigos y cuevas con depósitos prehistóricos (CASTIELLA, 1986: 146) y allí también se encuentra un imponente mirador natural que se conoce como Balcón de Lazkua. La Peña de Altikogaña está ocupada por un poblado fortificado de la II. Edad del Hierro y la de Bargagorria por otro poblado más pequeño fechado en la I. Edad del Hierro y que constituiría el antecedente de Altikogaña (ARMENDÁRIZ, 2010a) (fig. 2).

De entre todos estos yacimientos ha sido Altikogaña el que mayor atención ha merecido debido al interesante conjunto de materiales hallados en el mismo (CASTIELLA, 1986: 146-150 y Láms. I-III; 1989; CASTIELLA y SESMA, 1989; ARMENDÁRIZ, 2010a), entre los que se encuentra un lote de armamento

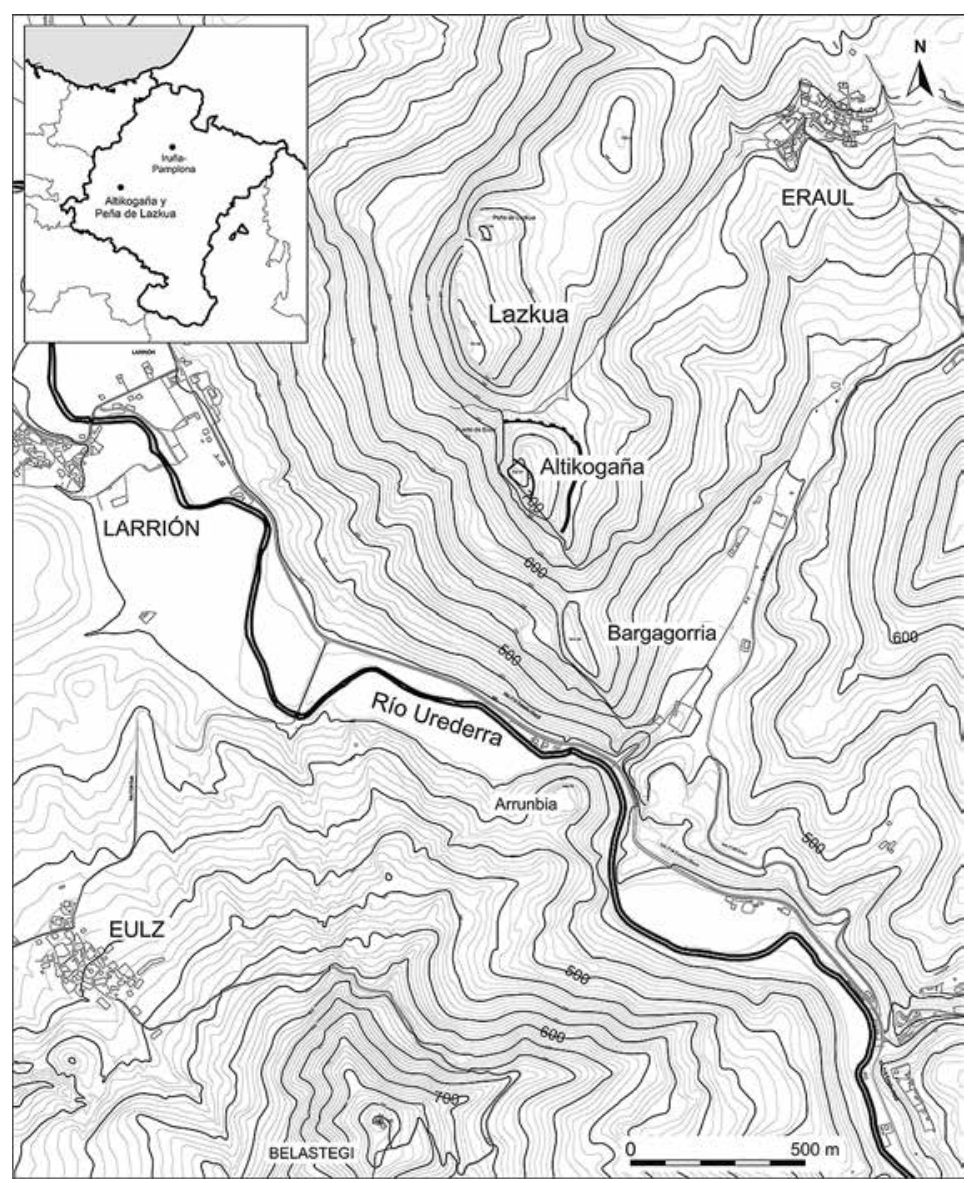

Fig. 2. Altikogaña y Lazkua en su contexto geográfico: las Peñas de Larrion y el paso del Urederra. / Altikogana and Lazkua in its geographical context: Larrion crags and the pass of the river Urederra. 
romano de asalto cuya correcta interpretación permitió identificar a Altikogaña como un poblado asaltado y destruido por tropas romanas (MARTíNEZ, 2003).

El poblado de Altikogaña aún tiene mucho que decir y por eso, entre 2013 y 2014, se procedió de nuevo a la revisión de parte del material metálico depositado en el Centro de Estudios Tierra Estella-Lizarrerriko Ikastetxea (CETE-LI) y a la visita del yacimiento. Uno de los resultados de ese estudio del material fue la identificación de un nuevo signum equitum en la colección antigua que había pasado totalmente inadvertido hasta la fecha. La visita al yacimiento y su entorno, por su parte, permitió confirmar el carácter de santuario del lugar que hoy se conoce como el Balcón de Lazkua. En estas líneas se recoge el estudio de ambos y de su contexto arqueológico.

\section{ALTIKOGAÑA. EL CONTEXTO DEL HALLAZGO}

\subsection{El poblado}

La peña de Altikogaña presenta hacia el oeste un cortado natural de paredes verticales y hacia el este una ladera de fuerte pendiente que está ocupada en su totalidad por el poblado (fig. 3). La cima se encuentra a $732 \mathrm{~m}$ de altitud, con un desnivel acusado respecto al fondo del valle del Urederra de algo más de 250 m. Su posición y características lo convierten en un hito geográfico fácilmente identificable y le confieren además unas amplias vistas sobre los valles históricos de Allín y Valdega, hacia el oeste, y sobre los valles de Yerri y Guesálaz hacia el este. Desde esta posición controla visualmente el desfiladero de San Fausto. También controla directamente el camino de herradura que transcurre por el puerto de Eraul y que pasa al pie de la muraIla. Este viejo y tortuoso camino también se ha utilizado ocasionalmente como vía pecuaria hacia los pastos de la sierra de Andía. Todo ello, junto a las características defensivas naturales de la peña, explican la presencia de este poblado en este lugar.

El emplazamiento estratégico de esta peña y la disponibilidad de material constructivo en el mismo lugar propiciaron que se llevaran a cabo varias obras defensivas y de acondicionamiento del espacio para acomodar un poblado fortificado, pese a que la fuerte pendiente del recinto no era la más adecuada para el establecimiento de las edificaciones ni la más idónea para su óptima defensa, algo que intentarán paliar con la creación de un segundo cinturón defensivo en la parte alta del poblado. Esta necesidad de un mayor esfuerzo constructivo para la ubicación de las viviendas queda plasmada en una fuerte artificialización del espacio en forma de terrazas.

Una muralla perimetral cierra este poblado contra el cortado natural y delimita un espacio interior de unas 4,5 ha (fig. 3). Cerca de la cima, una segunda línea de muralla completa el sistema defensivo creando un espacio a modo de acrópolis. En la línea de defensa exterior se observa un punto de acceso sencillo en el extremo sur, junto a la línea de cortado natural. Hacia el noreste de la muralla, un potente canchal de derrumbe y un quiebro en el trazado podrían estar indicando la presencia de una puerta con alguna estructura de refuerzo. Un escalonamiento o aterrazamiento del terreno con una pequeña depresión en su interior recorre la muralla por el exterior e indica la presencia de un foso que completa la defensa. Esta depresión no se observa hacia el norte, pero muy posiblemente también contaba con foso en esta zona puesto que allí delante hay un espacioso collado junto al Puerto de Eraul, lo que significa que era el punto más accesible y vulnerable por lo que tuvo que estar reforzado.

Son pocos los datos de que disponemos sobre el diseño y ejecución de esta defensa y, a falta de una excavación sistemática, sólo puede realizarse una aproximación a partir de los datos de superficie. Esta muralla exterior presenta un trazado de tipo lineal adaptado al terreno con un desarrollo horizontal muy regular. Se ha empleado mampostería de caliza local sin escuadrar o parcialmente escuadrada pero seleccionada para levantar un paramento con careado exterior. Muy posiblemente se haya empleado la técnica del doble paramento con relleno interior. La muralla se ha diseñado cumpliendo una doble función defensiva y de aterrazamiento interior del espacio debido a la fuerte pendiente de la ladera.

La muralla superior cumple igualmente esta función defensiva y de aterrazamiento y se distingue de los aterrazamientos habitacionales a partir de dos características definitorias. Por un lado presenta un canchal de derrumbe muy potente que no se observa en el resto de bancales y que da a entender la presencia de una estructura reforzada. Por otro lado, esta estructura se desarrolla a lo largo de toda la ladera sin interrupción y se adosa al cortado natural, con dos pequeños vanos en ambos extremos, junto al cortado, que corresponden a los puntos de acceso. Un trazado de estas características impide una circulación normalizada por el interior del poblado, algo que no se observa en el diseño general del resto de los aterrazamientos interiores, lo que unido a las características anteriores, permite identificar esta estructura como una segunda muralla. Esta muralla presenta también un trazado lineal con un desarrollo en horizontal muy regular adaptado al terreno. Hacia el este, un corto tramo aún conserva un poco de su alzado, lo que permite ver una obra con mampostería de caliza local bastante regular, dispuesta en hiladas y con un careado exterior.

Debido a la fuerte pendiente, todo el espacio interior está aterrazado como acondicionamiento del espacio para su habitación. Estos aterrazamientos interiores se ejecutaron con muros de mampostería de caliza local en seco para reforzarlos y se dispusieron coordinados de forma concéntrica con interrupciones en su trazado a modo de puntos de paso que facilitaran el tránsito por el interior del poblado quedando a la vista un abigarrado conjunto de bancales comunicados entre ellos. 


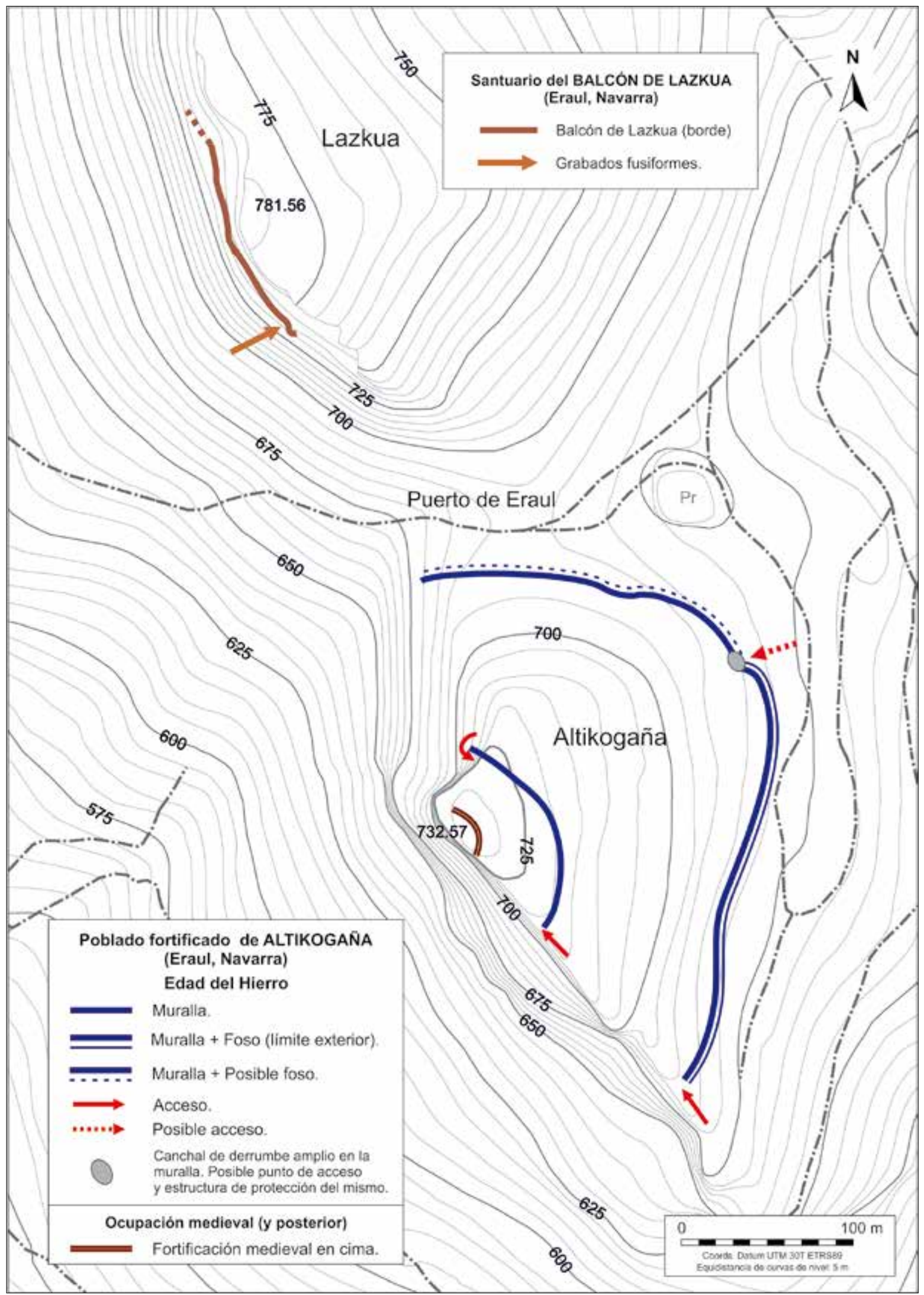

Fig. 3. Altikogaña y Lazkua. Plano topográfico con la ubicación de ambos y las estructuras destacadas. / Altikogaña and Lazkua. Topographic map with the location of both and prominent structures. 
Se ha hallado una variada colección de materiales (cerámicos, líticos, etc.) entre los que destacan los metálicos (fíbulas objetos de adorno y monedas) (CASTIELLA, 1986: 146-150 y Láms. I-III; 1989; CASTIELLA y SESMA, 1989) con un abanico cronológico que se extiende entre los ss. V-I a.e. (Armendáriz 2010a: 97-99).

El final del poblado se produjo de forma brusca, tras el asalto y destrucción del mismo por parte de tropas romanas. Entre los materiales hallados en este lugar se encuentra un lote de armamento que incluye proyectiles de honda (glans fundae) del tipo 2a de Völling (1990), varias puntas de flecha de tipo sirio y varias puntas de dardo para catapultas de tipo scorpio. A. Castiella y J. Sesma publicaron inicialmente este material como indígena (CASTIELLA y SESMA, 1989) pero la revisión posterior por parte de uno de nosotros de este armamento permitió identificarlo como armamento romano de asalto y concluir que correspondía a los restos del asalto y destrucción del poblado por parte de tropas romanas ${ }^{1}$. Entre los materiales de Altikogaña se hallaban además una fíbula de tipo Alesia así como otra fíbula y un fragmento de pie con arranque del arco, ambas de tipo Durnacus². La fecha post quem del asalto se estableció a partir de la fíbula tipo Alesia, a la que se atribuye un origen militar asociado a los tiempos de Cesar, con una cronología de mediados del s. I. a.e. hasta el cambio de era ${ }^{3}$.

La vida del poblado de la Edad del Hierro finaliza tras la conquista romana pero la peña cuenta con ocupaciones posteriores en el entorno de la cima. Atendiendo a la importancia estratégica del emplazamiento, certificada por el asalto romano, cabe plantearse si no se dio una ocupación puntual, breve en el tiempo, por parte de las tropas romanas, igual que sucedió por ejemplo en el caso del castro de la Espina del Gallego (Corvera de Toranzo, Anievas y Arenas de Iguña, Cantabria) (PÓO et al., 2010), y que sigue una pauta de comportamiento habitual en el ejército romano que se rige por el control temporal de la plaza tomada en los contextos de guerra.

Lo que sí se constata es una ocupación romana algo posterior, posiblemente centrada en la cima, que viene representada por la presencia en el mencionado conjunto de materiales de dos fíbulas de tipo Durnacus con una cronología que se extiende desde época de Augusto hasta inicios del s. II d.e $e^{4}$. La propia cronología de estas fíbulas impide relacionar el asalto romano al poblado con esta fecha puesto que para época de Au- gusto los únicos conflictos bélicos en la península son las guerras de Roma contra cántabros y astures. Sobre esta ocupación son pocos los datos disponibles, pero atendiendo al tipo de emplazamiento, la ausencia de poblamiento romano como tal y al origen en el mundo militar romano de estas fíbulas, cabe plantear esta ocupación como militar romana y entenderla en un contexto más amplio poniéndola en relación con el puesto militar romano de Allide (Ibiriku, Yerri) (MARTíNEZ, 2009a; 2009b), y relacionarla con la nueva ordenación del territorio de época augústea.

Entre los materiales de Altikogaña se pueden observar algunas puntas de dardo de ballesta y objetos decorativos sobredorados de filiación claramente medieval. Estos hallazgos, unidos a la presencia en la parte superior de la peña de los restos de una pequeña muralla de $180 \mathrm{~cm}$ de anchura con fábrica de mampostería y argamasa de cal, evidencia la existencia de una ocupación de la cima en época medieval. Igualmente se aprecian varios mechinales en la roca que nos indican la presencia de entramados de madera para refugio de la pequeña guarnición que ocupó este puesto, que cabe poner en relación con las defensas de Estella, con quien mantiene contacto visual y de la que más allá de constatar su existencia poco sabemos a día de hoy (figs. 2 y 5). Es posible que los restos del poblado y de este espacio amurallado en particular se reocuparan en el contexto de las diferentes Guerras Carlistas puesto que se encuentra en la periferia del teatro de operaciones de varios enfrentamientos de este período. Así, se produjo el 19 de Agosto de 1834 la emboscada de San Fausto. Más tarde, el 5 de mayo de 1873, la conocida como "Batalla de Eraul" y, finalmente, el 27 de julio de 1874, la batalla de Muru. Aun así, esa posible reutilización no fue importante ya que no alteró de forma visible los elementos más antiguos ni marcó su impronta en la toponimia como ocurre en la vecina cima de Belastegi (Eulz, Allín) donde el paraje conocido como "El Fuerte" atestigua este uso.

\subsection{Función local y territorial del poblado}

Hay dos cuestiones importantes relacionadas con Altikogaña, una es la función que cumple el emplazamiento y la otra es su importancia con relación a otros emplazamientos de la zona. Todo ello nos da una idea de su posición geoestratégica y nos ayuda a entender mejor el contexto del hallazgo del signum equitum.

\footnotetext{
${ }^{1}$ El estudio de este lote de armamento se llevó a cabo en 1999 y los resultados se presentaron en público en el año 2000 , en el marco del II. Coloquio Internacional sobre la Romanización en Euskal Herria. Las actas de este congreso no llegaron a publicarse por lo que en el año 2003 se publicó una versión algo más reducida del estudio (Martínez, 2003).

2 Estas fíbulas fueron estudiadas y fechadas inicialmente por R. Erice (1995: nos 103, 315 y 316) e incorporadas al estudio de conjunto del material romano posteriormente por A. Martínez (2003: 166).

${ }^{3}$ Fíbula $n^{\circ} 103$ del catálogo de R. Erice que corresponde al tipo 19.1, variante de la Alesia (Erice, 1995: 92-93, 98-99 y lám. 13.103). Sobre el tipo Alesia también en M. Mariné, 2001: 205-207.

${ }^{4}$ Corresponden a los n 315 y 316 de R. Erice, que las cataloga como del tipo 20.5 (Erice, 1995: 121), una variante de la Aucissa. Equivalen al tipo Durnacus de Mariné; para el tipo Durnacus y su cronología vid. Mariné, 2001: 224-226.
} 
Tal y como ha constatado Armendáriz (2010: 102) el castro de Bargagorria presenta una cronología de la I. Edad del Hierro y constituye el precedente del poblamiento en Altikogaña. Esta continuidad en la ocupación del entorno debe ponerse en relación con el control directo del estrecho paso del Urederra, cuya salida se sitúa al pie de estas peñas, ya que el recorrido del Urederra constituye un paso natural que se dirige a los pastos de la sierra de Urbasa. Este paso constituye también una de las puertas de entrada al valle de Allín, de hecho, la posición al final del paso y su control visual del valle de Allín, nos indican además que Altikogaña debe vincularse en primera instancia con este valle y no con el aledaño de Yerri, máxime cuando en toda la extensión del valle, hasta la orilla izquierda del Ega, no hay ningún poblado fortificado que pueda suplir o compartir con Altikogaña ese dominio territorial. A ello debemos unir el hecho de que Altikogaña controla igualmente el conocido como Puerto de Eraul, que discurre justo al pie de su muralla. Altikogaña por lo tanto, es el poblado fortificado que regula el acceso al valle de Allín y controla sus recursos, algo que queda más evidente en la primera ocupación ubicada sobre la peña de Bargagorria. En el traslado de Bargagorria al nuevo emplazamiento de Altikogaña no apreciamos que se aporte nada determinante en relación con el territorio que le proporciona sus medios, e igualmente no parece suponer ninguna variación respecto a su situación con los demás poblados de la zona. Es decir, más que el resultado de un proceso sinecista, consideramos que este cambio de emplazamiento obedece a un aumento demográfico debido a un cúmulo de variables que con toda probabilidad permitieron un aumento de excedentes.

Así, tenemos que la posición geoestratégica del poblado viene a controlar los accesos orientales al valle de Allín, los más fáciles de defender debido a su complejidad orográfica, dejando totalmente desprotegida hacia el este la zona llana y más accesible que se prolonga hasta la margen izquierda del Ega. Esta ubicación, en apariencia inusual, resulta coherente si entendemos que en realidad la elección de Altikogaña obedece a la idea de interponerse entre sus áreas de explotación (hacia el Oeste) y sus vecinos del Este, con los cuales busca una "confrontación" visual, ya que desde este emplazamiento se da un contacto visual con los dos poblados más próximos, Iruñela y Muru (Yerri) (fig. 4.5 y 4.8). Este posicionamiento del poblado, además, nos resulta más explicable si convenimos en asignar el valle de Allín a distinta etnia que la de sus vecinos orientales a los cuales resulta lógico interpretar como vascones. Esto mismo se evidencia en la posición relativa respecto al territorio, ya que esa equidistancia territorial que se aprecia en los poblados del Este se rompe en este enclave que domina un territorio bastante mayor que el atribuible a esos otros poblados. No creemos que en este caso la unidad étnica implique un grupo políticamente cohesionado, pero sí consideramos que ese vínculo cultural implica una fluida interrelación en distintos planos. En cualquier caso, la ubicación de Altikogaña ignora la zona más accesible a sus terrenos y se posiciona dominando los abruptos pasos orientales. Esta extraña ubicación quizás pueda ser explicada de otra forma, pero nosotros consideramos que esa parte del Ega que supone una continuidad geográfica con el valle de Allín y la Berrueza, forma parte del mismo grupo humano.

Pasado el valle de Allín y siguiendo el curso del Urederra, el paso a Amescoa se hace por otro desfiladero conocido como Inzura y que también da nombre a un poblado que se asienta bajo los restos de lo que hoy se conoce como Ameskoazarra (ARMENDÁRIZ, 2010b) (fig. 4.3). Este asentamiento con carácter de control lo consideramos dependiente de Altikogaña ya que el lugar no reúne condiciones económicas para mantener una infraestructura de subsistencia que garantice la habitabilidad para un grupo numeroso. Algo que quedó atestiguado con la temprana desaparición de la población aforada por Sancho El Fuerte con la que pretendía neutralizar el peligro que suponía la nueva frontera creada tras la conquista castellana de 1200 y cuya defensa rápidamente pasó a ser dirigida por los emergentes linajes amescoanos (LAPUENTE, 1990).

Al norte del desfiladero, en Amescoa Alta, J. Armendáriz (2011: 97-101) ha localizado en Arnotegui (fig. 4.4) el poblado que parece explotar ese territorio y aunque parece lógico situar en la Amescoa Baja otro lugar similar a Arnotegui, sólo las prospecciones dilucidarán el dilema. De igual manera, en la parte oriental de este territorio los pasos a la sierra de Andía por su parte sur son controlados por los poblados que jalonan su piedemonte: Iruñela (Iruñela, Yerri) (ARMENDÁRIZ, 2008: $n^{\circ}$ 170), Rezumendía (Riezu, Yerri e Iturgoyen, Guesálaz) (ARMENDÁRIZ, 2008: $n^{\circ}$ 175) y el de San Salvador (Salinas de Oro $)^{5}$ (fig. 4.5, 4.6 y 4.7). Aunque es aventurado delimitar el perímetro de estos tres poblados últimos, la distribución de los materiales en superficie indica que su extensión se asemejaría a la de Altikogaña, aun teniendo en cuenta que esta dispersión superficial puede presentar un cierto margen de precisión, lo que podría variar parcialmente las conclusiones, aunque en este caso consideramos que de forma leve. De igual manera, esta relación de equidistancia y unos valores similares en cuanto a la extensión urbana nos permite colegir una relación de iguales en la que no vemos indicios de una jerarquización entre los poblados mencionados. Ni tan siquiera nos parece aceptable el proceso jerarquizador para el caso de Muru, junto a Abárzuza (fig. 4.8), que con un área aproximada de 1,8 ha (Armendáriz 2008: $\mathrm{n}^{\circ}$ 174) presenta menores valores de extensión pese a ser, junto a Iruñela, uno de los dos poblados orientales más próximos a Altikogaña. Para nosotros, Muru presenta similar posición de equidistancia que el resto de poblados que humanizan los valles de Yerri y Guesálaz en el

5 Inédito. 
final de este período. Así, consideramos el poblado que se situó junto a las actuales edificaciones de Murugarren (Yerri) (ARMENDÁRIZ, 2008: $n^{\circ}$ 172) (fig. 4.9) como parte de Muru. La visita al lugar no nos hace considerar que los escasos restos apreciados sean de mayor entidad que unas edificaciones auxiliares del poblado amurallado de Muru, ya que se encuentran en el interior de su área vital.

Otra cosa distinta es nuestra consideración de los poblados de Muru y Gasteluzar, ubicados en el término de Iturgoyen y que menciona J. Armendáriz (2011: 101-104 y 105-108, respectivamente) (fig. 4.10 y 4.11). La tradición oral nos llega considerando ambos lugares como castillos. Lógicamente, esa tradición tan solo nos refleja la interpretación del imaginario local para la comprensión del paisaje y de los hitos que lo jalonan. Junto a esta tradición local, que poco suele aportar en términos de explicación histórica, tenemos el apoyo de la toponimia y la evidencia de los restos, al menos para intentar ordenarlos cronológicamente, cosa aventurada, en parte, sin los datos que proporciona una excavación. Así tendríamos en el topónimo parlante de Muru un poblado que manifiesta su mayor potencia en la primera parte de la Edad del Hierro, tal como se observa a partir de la dispersión de los materiales de superficie en el antiguo paraje cultivado denominado "Las Eras de Muru". No creemos que este poblado tuviera importancia en el período histórico que estamos tocando debido a la práctica ausencia de materiales y restos de esa época, a su ubicación marginal e inapropiada para la explotación racional del entorno y a que se haya dentro del área vital del importante poblado de Rezumendia, en base a los claros parámetros de equidistancia que se aprecian en los poblados amurallados de la zona.

Más complejo resulta Gasteluzar ya que presenta unas características distintas a las de los castros cercanos. Su altura es claramente superior a la de éstos y su posición defensiva es determinante para interpretar el

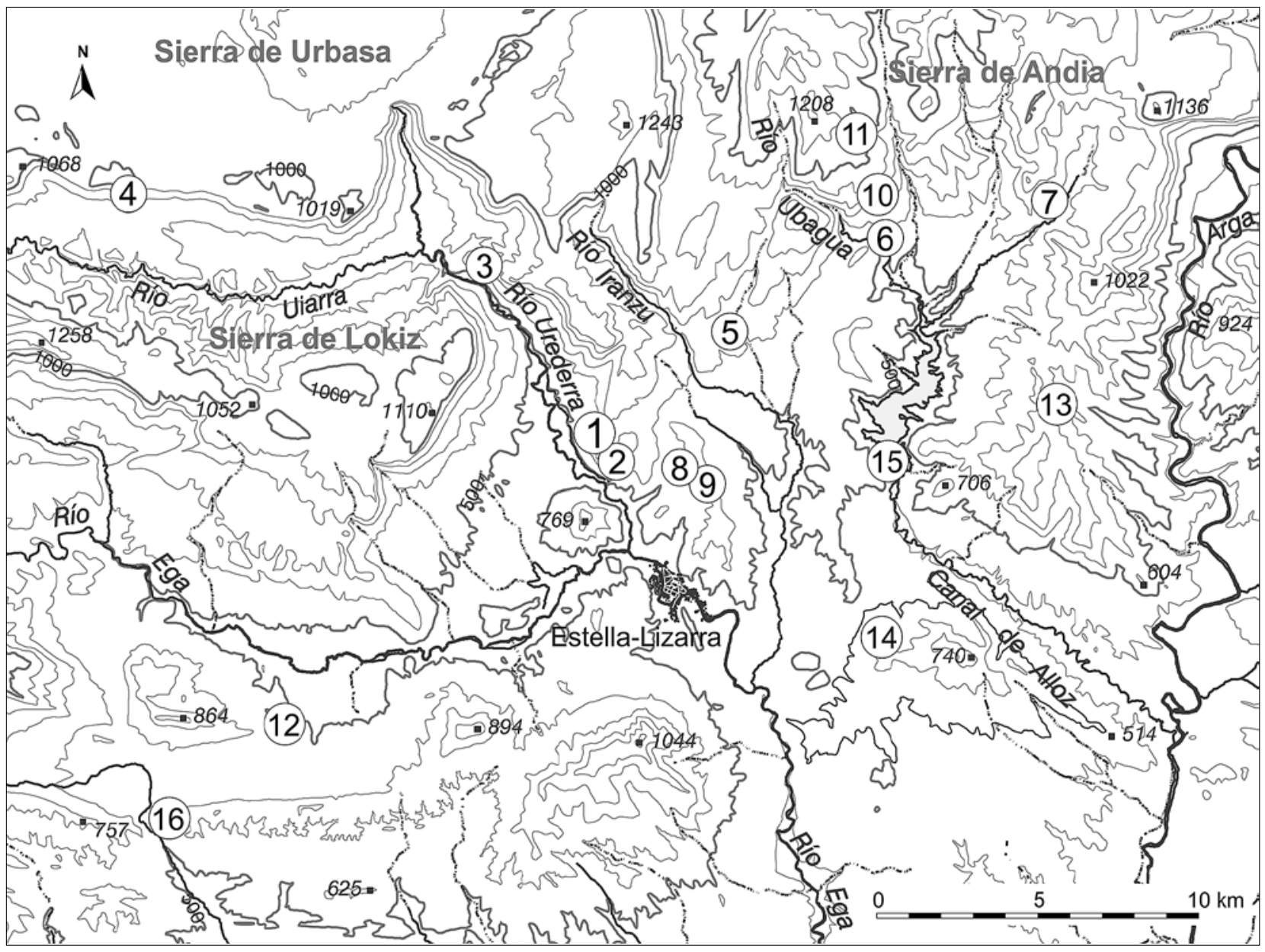

Fig. 4. Poblados citados en el texto: 1. Altikogaña (Eraul); 2. Bargagorria (Eraul); 3. Inzura / Ameskoazarra (Artaza); 4. Peña Arnotegui (Aranache y Larraona); 5. Iruñela (Iruñela); 6. Rezumendia (Riezu e Iturgoyen); 7. San Salvador (Salinas de Oro); 8. Muru (Yerri); 9. Murugarren (Murugarren); 10. Muru (Iturgoyen); 11. Gazteluzar (Iturgoyen); 12. Pozo de La Mora (Legaria y Oco); 13. San Cristóbal (Guirguillano); 14. Mauriáin (Villatuerta); 15. Murumendi (Alloz); 16. Murillo (Mues). / Villages mentioned in the text: 1. Altikogaña (Eraul); 2. Bargagorria (Eraul); 3. Inzura / Ameskoazarra (Artaza); 4. Peña Arnotegui (Aranache y Larraona); 5. Iruñela (Iruñela); 6. Rezumendia (Riezu e Iturgoyen); 7. San Salvador (Salinas de Oro); 8. Muru (Yerri); 9. Murugarren (Murugarren); 10. Muru (Iturgoyen); 11. Gazteluzar (Iturgoyen); 12. Pozo de La Mora (Legaria y Oco); 13. San Cristóbal (Guirguillano); 14. Mauriáin (Villatuerta); 15. Murumendi (Alloz); 16. Murillo (Mues). 
recinto ya que su control territorial de los recursos más inmediatos es distinto al que presentan otros castros. Gasteluzar, a diferencia de los castros de la zona, se ubica en medio del monte y apenas tiene acceso cercano a lugares cultivables, sin embargo, su control visual de los accesos naturales a Yerri y Guesálaz se asemeja al de las fortalezas medievales. Por lo tanto, a partir del topónimo, de la conservación y factura de las estructuras defensivas así como por su ubicación exclusivamente defensiva, consideramos Gasteluzar como un recinto defensivo relacionable con el colapso de la tardoantigüedad. Evidentemente, volvemos a reiterar que esta secuencia cronológica que a nosotros se nos hace coherente, es una hipótesis de trabajo que debiera ser contrastada mediante una intervención arqueológica.

Finalmente, en Muru tenemos la misma situación en Inzura: un lugar inapropiado para la segunda Edad del Hierro y sin ningún paralelo en la zona. Así que tenemos que esa ubicación enriscada, hace que el lugar se encastille en época medieval dejando evidentes restos de carácter defensivo. Estos restos medievales hacen bueno el calificativo de zaharra-antiguo- que conserva el topónimo Gasteluzar y ratifica la fijación cronológica que atribuimos a este recinto defensivo. En cambio, el topónimo Muru sobrevivió a la fábrica de la fortaleza medieval, cuya función nos llega en el imaginario popular como lugar de defensa para los ataques de los moros. Esa legendaria función, los naturales, la suponen compartida con el lugar de Gasteluzar.

A partir de todo lo anteriormente expuesto es como se define el papel que ocupa Altikogaña en el territorio. J. Armendáriz (2010a: 111) se refiere a este núcleo de población como un oppidum, fundamentalmente por tres razones: posición estratégica del emplazamiento, área que ocupa, que la calcula en unas siete hectáreas (ARMENDÁRIZ, 2010a: 100) y, sobre todo, la importancia que le otorga al núcleo el hecho de haber sido asaltado por tropas romanas. De tal forma que lo interpreta como un núcleo que sigue el modelo de ciudad-estado que jerarquiza de forma nítida el poblamiento de otros poblados o castros "satélite" de muchísima menor entidad. En este orden de cosas, se complementaría en funciones con otros poblados de la comarca, que identifica igualmente como oppida, tales como Pozo de la Mora (Legaria y Oco), San Cristóbal de Guirguillano (Guirguillano), Mauriáin (Villatuerta) y tal vez Murumendi (Alloz) (ARMENDÁRIZ, 2008: nos 185, 165, 168 y 169; 2010a: 111) (fig. 4. nos 12, 13, 14 y 15).

Aquí en cambio nos referimos a Altikogaña como poblado fortificado y no como oppidum. La definición de un núcleo de población determinado como oppidum es el resultado de la combinación de diferentes características. En términos generales y en comparación con un castro al uso, se puede hablar de recintos con una mayor proyección estratégica y del control del territorio así como de las vías de comunicación, que vertebran y jerarquizan el territorio. Además, estos núcleos poseen una mayor complejidad general en sus estructuras defensivas y urbanísticas y un mayor tamaño relativo según cada área geográfica. Así tenemos que un mínimo trazado planificado y ordenado de las calles y espacios públicos ha sido otro criterio valorado para interpretar un poblado como oppidum. En cuanto a la estructura vecinal, esta es compleja, con numerosas familias vecinas que conviven juntas en régimen de mutua ayuda y cooperación (solidaridad y reciprocidad). El oppidum funcionaría también como un lugar de depósito de reservas estratégicas colectivas y de celebración de reuniones religiosas, sociales y políticas. Su extensión media se sitúa entre las 10 y las $20 \mathrm{Ha}$. aunque también hay núcleos que superan este tamaño (TORRES-MARTíNEZ, 2011: 276-278)

Tomando como referencia esos criterios generales, el término oppidum se viene asignando a grandes núcleos de población como Monte Bernorio (Villarén de Valdivia, Palencia), Numancia (Garray, Soria) o Pintia (Padilla de Duero, Valladolid), por citar algunos ejemplos, que son equiparables a ciudades a partir del área que ocupan, sistemas defensivos, capacidad económica, proyección territorial, etc.

El área de ocupación calculada para Altikogaña, a partir de la revisión a pie de terreno del sistema defensivo, la estimamos en unas 4,5 hectáreas. Esto lo sitúa a parecido nivel de los poblados que flanquean el acceso a la sierra de Andia, anteriormente mencionados, y similar a las 4 hectáreas de Murumendi (Alloz, valle de Yerri).

Por lo tanto, las características generales del poblado no encajan en el modelo de oppidum. Esto no significa que Altikogaña carezca de importancia, de hecho, es seguro que tuvo que cumplir una función de lugar central en el contexto de su comarca o entorno más próximo, pero no de una ciudad-estado como tal sino más bien como un poblado de cierta entidad vinculado fundamentalmente al valle de Allín.

\section{EL SIGNUM EQUITUM}

\subsection{Descripción}

Se trata de un objeto de bronce, posiblemente fundido, con un esquema compositivo a partir de dos mitades delanteras de caballo contrapuestas que se presentan unidas por el cuerpo ${ }^{6}$ (figs. 5 y 6). La composición es simétrica con un diseño muy estilizado y esquemático pero reconocible. Los cuerpos, cuellos y patas se han diseñado estrechos y alargados, con líneas paralelas, las cabezas de los caballos son estrechas de perfil triangular. El único rasgo anatómico individualizado son las ore-

\footnotetext{
${ }^{6}$ Para los criterios de descripción de esta pieza y las siguientes, se han tomado como referencia, fundamentalmente, los trabajos de Almagro-Gorbea y Torres (1999), Lorrio (2010) y Lorrio y Graels (2013), a efectos de poder compatibilizar los datos.
} 


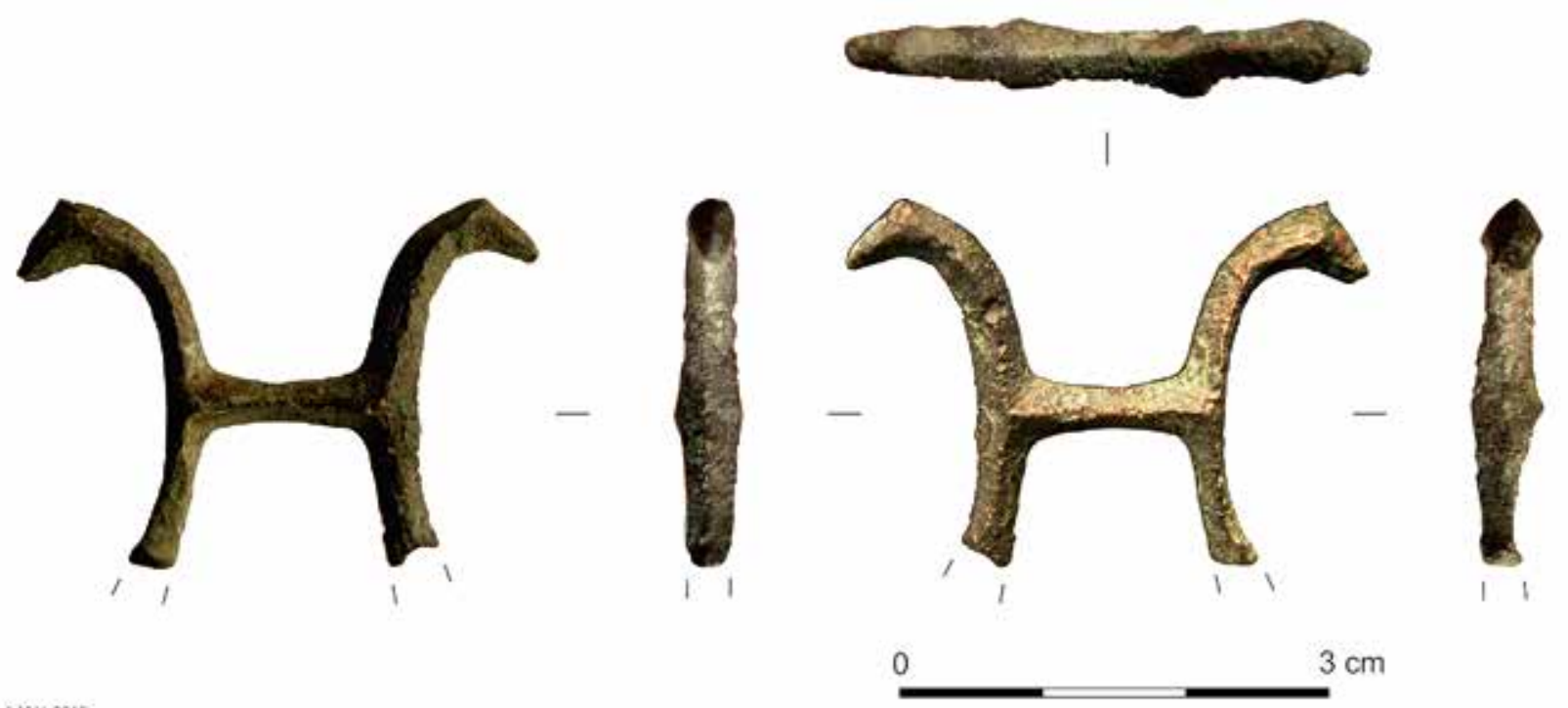

Fig. 5. Altikogaña. Signum equitum (Fotos: A.M.V. 2013). / Altikogaña. Signum equitum (Photos: A.M.V. 2013).

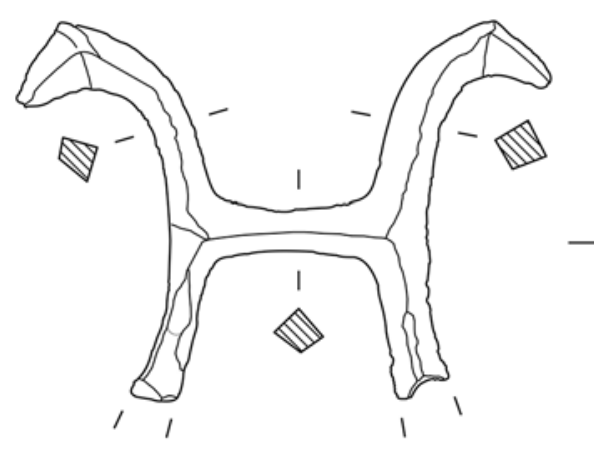

A.M.V. 2013

Fig. 6. Altikogaña. Signum equitum (Dibujo: A.M.V. 2013). / Altikogaña. Signum equitum (Drawing: A.M.V. 2013).

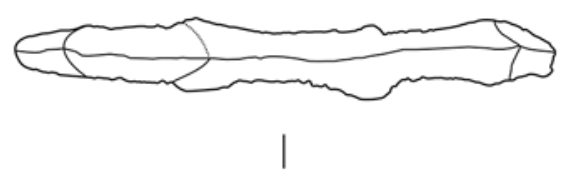

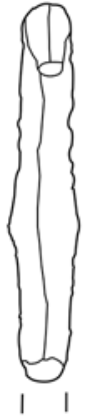

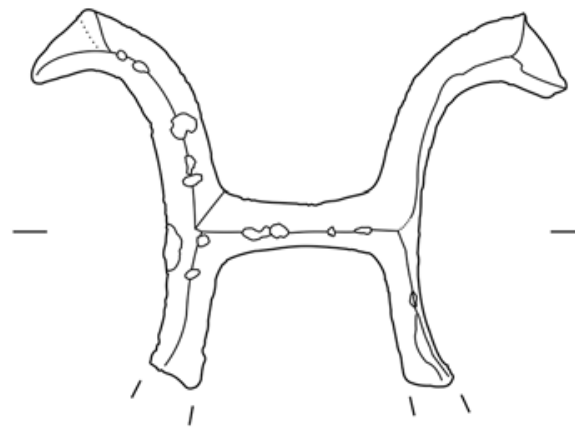

$3 \mathrm{~cm}$ jas, representadas mediante un engrosamiento único, de perfil apuntado y orientadas hacia arriba. El relieve de la pieza se ha reducido a la mínima expresión por lo que los perfiles generales son aplanados, por eso, para conseguir una cierta impresión de volumen, los diferentes elementos compositivos presentan secciones cuadradas/ romboidales lo que confiere a ambos prótomos cuerpos facetados. La pátina original se encuentra perdida en gran medida por lo que no es posible saber si tuvo algún elemento decorativo como círculos, líneas, etc.

Dos fracturas en la base, en las patas de los caballos, indican la pérdida de un elemento del objeto, una prolongación del mismo, que tuvo que corresponder, casi con toda seguridad, al enmangue. Sobre este sistema de enmangue y el diseño que debió tener la pieza en origen, cuando estaba completa, no disponemos de ningún dato.

Altura total: 2,49 cm; ancho máximo: 3,38 cm; Espesor medio; 0,35 cm; peso: 3,56 gr.

\subsection{Paralelos y cronología}

Cabe señalar tres características generales para el signum equitum de Altikogaña: composición simétrica a partir de dos mitades delanteras de caballo contrapuestas, esquematismo en el diseño y reducido tamaño. Atendiendo a esas características, una pieza muy similar se encuentra entre las colecciones antiguas atribuidas al oppidum de Monte Bernorio (Villarén de Valdivia, Palencia). Se conoce únicamente a través de una 
foto en la que aparece junto a otras piezas (NAVARRO, 1939: 235) y se desconoce su paradero por lo que no ha podido ser revisada (fig. 7)

Se trata de un objeto de material desconocido, presumiblemente bronce, de técnica de fabricación igualmente desconocida. Se compone de dos mitades delanteras de caballo unidas por el cuerpo de forma simétrica, diseñadas en un estilo esquemático. Parece estar fracturado en la base igual que la pieza de Altikogaña. Presenta cuello estrecho y alargado de líneas paralelas, morro esquemático de perfil ligeramente triangular, con orejas puntiagudas y hacia arriba. El cuello y lomo de los animales se encuentra facetado, el resto del cuerpo es difícil de precisar. No presenta decoración. Se desconocen las dimensiones.

No disponemos de una fechación directa para el signum de Altikogaña ni para su paralelo más próximo. Una fechación relativa podría proporcionarla la combinación de la cronología de ocupación y final del pobla-

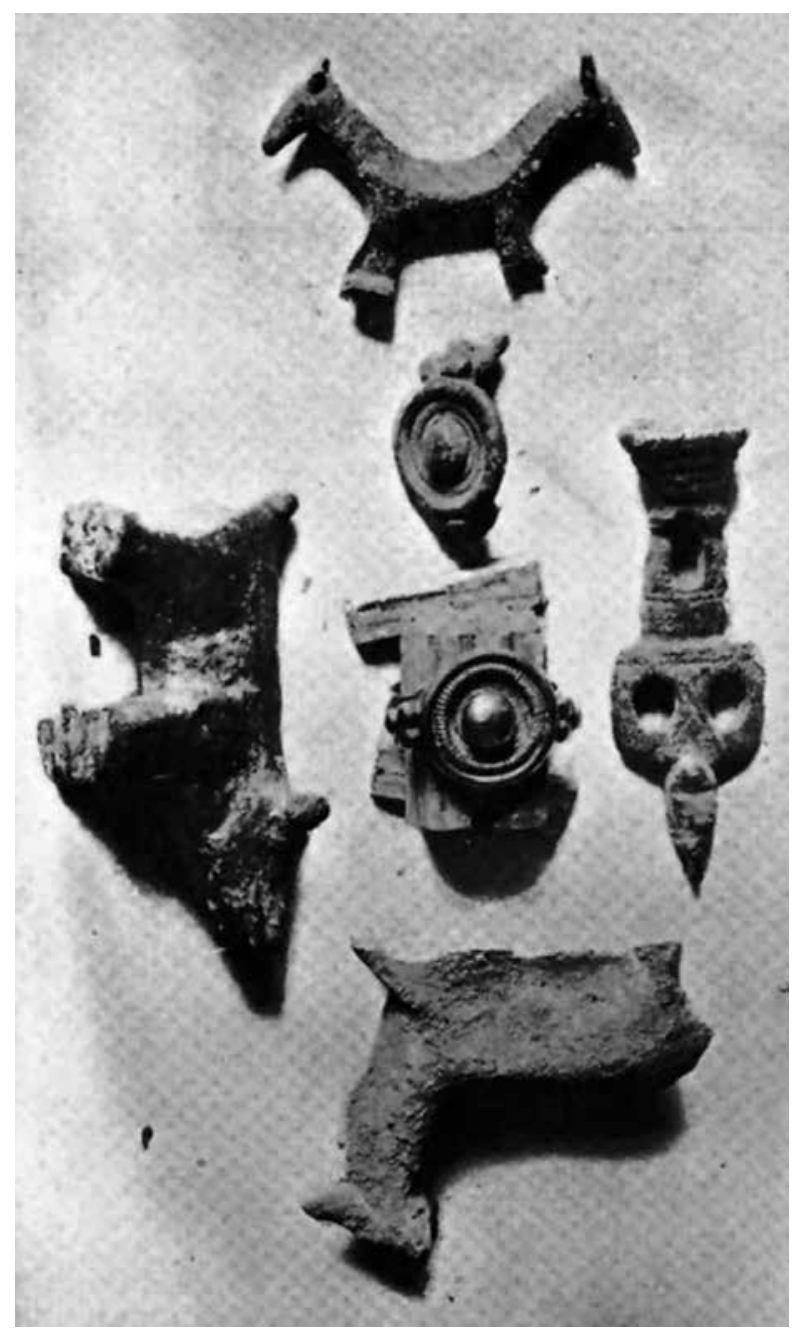

Fig. 7. Hallazgos de Monte Bernorio (Villarén de Valdivia, Palencia) según Navarro (1939: 235). / Finds from Monte Bernorio (Villaren de Valdivia, Palencia) according to Navarro (1939: 235) do con la cronología de los rasgos estilísticos en comparación con los signa equitum celtibéricos.

Altikogaña desarrolla toda su vida en la II. Edad del Hierro con un inicio a partir de sus materiales en el s. V. a.e. (ARMENDÁRIZ, 2010a: 99) y su final queda marcado por la destrucción romana. La destrucción del poblado marca una fecha ante quem y es una de las razones que pueden explicar la presencia en el yacimiento de parte del material indígena. No existe unanimidad en torno a esa fecha y son básicamente dos las opiniones en torno a este tema. Tal y como se ha mencionado anteriormente, por nuestra parte fechamos el asalto romano a mediados del s. I. a.e., en el contexto del Bellum Civile (48-46 a.C.) a partir de la fíbula de tipo Alesia presente en el conjunto de materiales romanos.

J. Armendáriz, por su parte, fecha el asalto romano al poblado en el contexto de las Guerras Sertorianas (7673 a.e.) argumentando fundamentalmente que esa parte del valle del Ebro ya estaba muy romanizada para el s. II a.e., que el armamento recuperado puede adscribirse a ese período y que arqueológicamente se constata el desarrollo de diferentes episodios bélicos de este período en suelo navarro a partir de la destrucción del poblado berón de La Custodia (Viana, Navarra) y de hallazgos dispersos en la Cuenca de Pamplona, Fitero-Cintruénigo (Navarra), etc. (ARMENDÁRIZ, 2010a: 112).

Sin embargo, esta fechación realizada por Armendáriz no se sostiene desde un punto de vista arqueológico y frente a ello cabe argumentar lo siguiente:

1. El registro arqueológico de Altikogaña no presenta ningún indicio de romanización previo al asalto y destrucción del poblado, por lo que el grado de romanización que se le atribuye al valle del Ebro no puede hacerse extensible sin más al valle de Allín en general ni a Altikogaña en particular sin una contrastación arqueológica que lo refrende.

2. Efectivamente, existen claras evidencias del conflicto sertoriano en suelo navarro, pero eso no obliga a atribuir toda evidencia de conflicto a ese período, es el registro arqueológico el que determina la cronología de un episodio bélico.

3. La presencia en el conjunto de materiales de una fíbula de tipo Alesia choca con la premisa de Armendáriz de fechación en época sertoriana del asalto a Altikogaña, contradicción que resuelve sacando del conjunto la fíbula, argumentando que el armamento militar se puede adscribir tipológicamente a ese período y explicando la presencia de la fíbula en el registro arqueológico como una pérdida casual. Pero esto tampoco se sostiene arqueológicamente, puesto que desde un punto de vista tipológico el material militar es perfectamente compatible con la cronología de la fíbula, lo que significa que más allá de la premisa cronológica de Armendáriz no existe ninguna razón de orden arqueológico que justifique retirar del conjunto esta fíbula. 
Pero no sólo eso, desde un punto de vista tipológico resulta muy significativa la presencia de puntas de flecha de tipo sirio $^{7}$ en el conjunto de Altikogaña, puntas de flecha que no se encuentran representadas en ninguno de los hallazgos de material militar romano del período sertoriano producidos en Navarra y que, en cambio, encontramos ampliamente representadas en el registro de episodios bélicos posteriores de las Guerras Cántabras, como en el asalto romano al oppidum de Monte Bernorio (Villarén de Valdivia, Palencia) (TORRES-MARTíNEZ, et al. 2012) o en el asedio romano de La Loma (Santibáñez de la Peña, Palencia) (PERALTA, 2008), lo que significa que desde el punto de vista tipológico, el conjunto del material militar debiera fecharse con más probabilidad en la segunda mitad del s. I. a.e., siguiendo esa tendencia que demuestra el registro arqueológico según la cual desde los tiempos de Cesar en adelante se va dando una sustitución progresiva de los cuerpos auxiliares de funditores (honderos) a favor de los sagitarii (arqueros) a partir de un reclutamiento más numeroso y organizado de estos (RENOUX, 2010: 21-29.), hasta llegar a las Guerras Cántabras donde estos últimos presentan un claro predominio sobre los otros.

Todo ello, por lo tanto, indica que la fecha de destrucción del poblado se sitúa a partir de mediados del s. I. a.e., probablemente en el contexto del Bellum Civile, y que esa es la fecha ante quem para los materiales indígenas de Altikogaña.

En cuanto a la cronología relativa del signum, una referencia la encontramos en la tipología de los signa equitum celtibéricos propuesta por Lorrio y Graels (2013: 206-216), quizás por entender la celtiberia como posible foco difusor. Tomando como referencia la composición simétrica de dos mitades delanteras de cabaIlo contrapuestas, el esquema encuentra sus paralelos más próximos en los hallazgos de la necrópolis de Numancia (Garray, Soria) (JIMENO et al. 2004: 167-170) identificados como signa equitum por Almagro-Gorbea y Torres (1999: 227), tipo para el que se establece una fecha de inicio en un momento avanzado del s. II a.e. con un final en torno a las Guerras Sertorianas.

En resumen, la fecha relativa que se propone como más probable para el signum equitum de Altikogaña, a partir de los datos disponibles, se sitúa entre finales del s. II. a.e. y mediados del s. I. a.e.

\subsection{Tipos y grupos}

A medida que se producen nuevos hallazgos e identificaciones de signa equitum algo que se observa progresivamente es el paralelismo entre algunos ejemplares y la posibilidad de agruparlos en tipos. El paralelismo formal entre el signum de Altikogaña y el ejemplar de Monte Bernorio invitan a su agrupamiento en un nuevo tipo (fig. 8). Definir un tipo únicamente con dos ejemplares no resulta definitivo, pero sí es algo que puede plantearse razonablemente como hipótesis de trabajo. Por lo tanto, en este caso, se plantea la existencia de un tipo que se define por un esquema compositivo simétrico a partir de dos mitades delanteras de caballo contrapuestas, un esquematismo general en su diseño y un reducido tamaño. Sobre los enmangues, no disponemos de datos, pero atendiendo al reducido tamaño, cabe proponer el uso de enmangues en espiga.

Un ejemplo de grupo que interesa señalar en relación al signum de Altikogaña es el de los signa equitum de tipo cántabro (MARTÍNEZ y FERNÁNDEZ, en prensa). El hallazgo de un nuevo signum equitum en el poblado fortificado de El Otero (Rueda de Pisuerga, Palencia) (fig. 9.1) y su claro paralelismo tipológico con el hallado en Santa Marina (Valdeolea, Cantabria) (FERNÁNDEZ y BOLADO, 2011: 325-326) (fig. 9.2), permitió despejar las dudas sobre la noticia de dos hallazgos procedentes del oppidum de La Ulaña (Humada, Burgos) (PERALTA, 2003: fig. 75) (fig. 9.3 y 9.4) y confirmar en conjunto la existencia de un grupo tipológico con dos variantes. Todos esos ejemplares tienen en común además su hallazgo en el contexto geográfico de la Cantabria Histórica.

La definición de ese grupo resulta interesante puesto que el único paralelo conocido para el ejemplar de Altikogaña se encuentra precisamente en el ejemplar de Monte Bernorio (Villarén de Valdivia), uno de los principales oppida de la Cantabria Histórica, y sin embargo es de una tipología diferente (fig. 9.5). Esta circunstancia no representa un obstáculo desde el punto de vista tipológico para su agrupamiento con el ejemplar de Altikogaña, pero sí es un dato a tener en cuenta de cara a proponer en un momento dado el origen del tipo o bien su adscripción étnica.

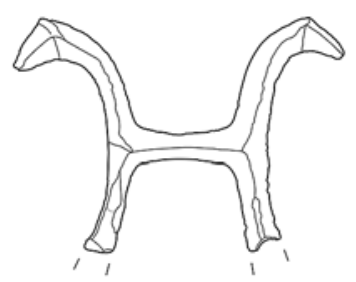

1

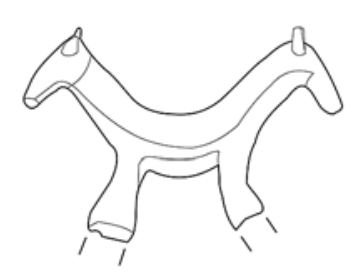

2
Fig. 8. Signa equitum: 1. Altikogaña (Eraul, Navarra). 2. Monte Bernorio (Villarén de Valdivia, Palencia) (Figs. A.M.V. 2013; $n^{\circ} 2$ a partir de foto de Navarro, 1939: 235). Sin escala. / Signa equitum: 1. Altikogaña (Eraul, Navarra). 2. Monte Bernorio (Villarén de Valdivia, Palencia). Figs. A.M.V. 2013 (No. 2 according to a photo of Navarro, 1939: 235). Without scale.

\footnotetext{
7 Sobre la tipología de las puntas de flecha en general y este tipo en particular vid. Torres-Martínez et al., 2013. Sobre las puntas de flecha de tipo sirio en Altikogaña vid. Martínez, 2003.
} 

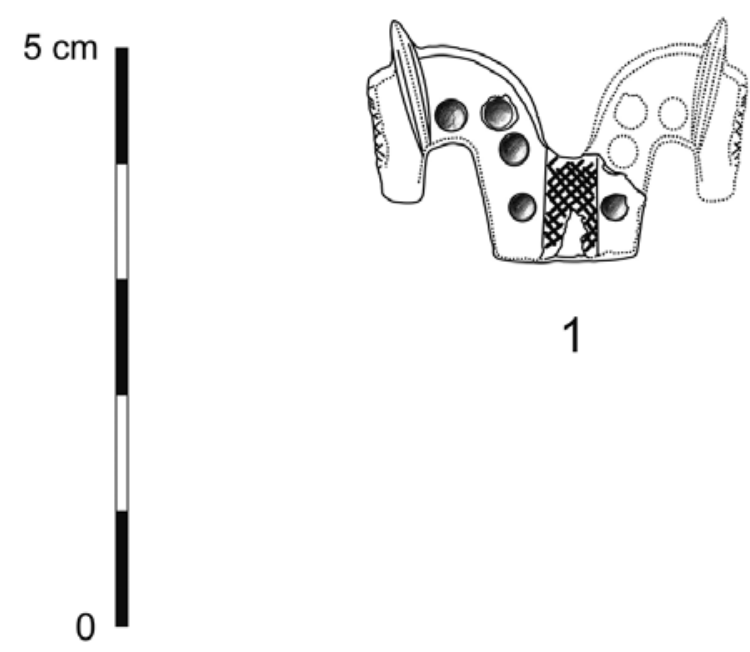

1

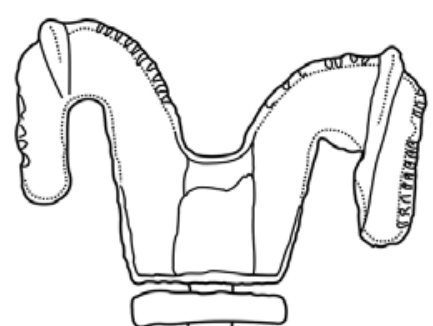

年

2

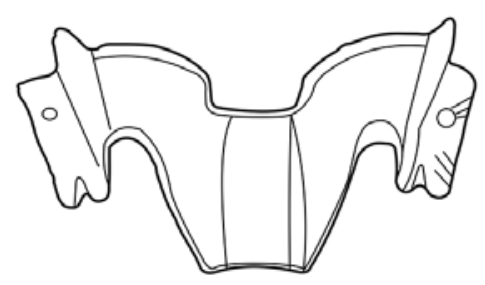

3

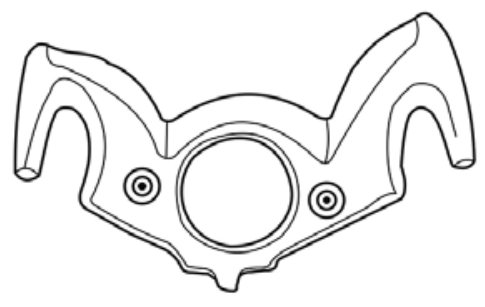

4

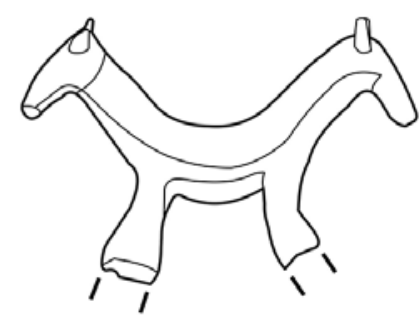

5

Fig. 9. Signa equitum de la Cantabria Histórica y signum equitum atribuido a Monte Bernorio: 1. El Otero (Rueda de Pisuerga, Palencia) (A.M.V. 2013); 2. Santa Marina (Valdeolea, Cantabria) (A.M.V. 2013 a partir de Fernández y Bolado, 2011: 325-326); 3 y 4. La Ulaña (Humada, Burgos) (A.M.V. 2013 a partir de foto de Peralta, 2003: fig. 75); 5. Monte Bernorio (Villarén de Valdivia, Palencia) (A.M.V. 2013 a partir de foto de Navarro, 1939: 235). Figs. 1 y 2 con escala; figs. 3, 4 y 5 sin escala. / Signa equitum of the historical Cantabria and signum equitum attributed to Monte Bernorio: 1. El Otero (Rueda de Pisuerga, Palencia) (A.M.V. 2013); 2. Santa Marina (Valdeolea, Cantabria) (A.M.V. 2013 from Fernández and Bolado, 2011: 325-326); 3 and 4. La Ulaña (Humada, Burgos) (A.M.V. 2013 from photo of Peralta, 2003: fig. 75); 5. Monte Bernorio (Villarén de Valdivia, Palencia) (A.M.V. 2013 from photo of Navarro, 1939: 235). Figs. 1 and 2 with scale; figs. 3,4 and 5 without scale.

Tal y como se ha mencionado anteriormente, la única información disponible es una foto en la que aparece junto a otras piezas (NAVARRO, 1939: 235) y se desconoce su paradero. Este ejemplar forma parte de alguna colección antigua cuya revisión posterior, cuando ha sido posible, ha permitido constatar que si bien es cierto que la mayor parte de los materiales atribuidos a Monte Bernorio proceden efectivamente de allí, hay también algunos objetos muy concretos cuya procedencia es diferente, caso por ejemplo de un gancho de carne del Bronce Final que pudo identificarse finalmente como procedente de Cantabrana (Burgos) ${ }^{8}$. En ese orden de cosas, encontramos que en la misma lámina que el signum de Monte Bernorio aparece también una figura, aparentemente de bronce, de una tipología cuyo único paralelo se encuentra en otra figura procedente del poblado berón de La Hoya (Laguardia, Araba) (CAPRILE, 1986: 151-152, lám. XVIII.13) (fig. 7). Tampoco encontramos paralelos para esta pieza entre los materiales antiguos de Monte Bernorio publicados por R. Moro (1891: 432-437) o W. Schüle (1969) ni entre los procedentes de las excavaciones recientes (TORRES-MARTíNEZ et al., 2012; 2013). Todo ello no impide establecer la procedencia de esa pieza en Monte Bernorio, pero sí indica que ante el hallazgo de Altikogaña y el conjunto de circunstancias expuestas, resulta a priori más razonable proponer el origen del tipo aquí, con un hallazgo contrastado, que en la Cantabria Histórica.

\footnotetext{
${ }^{8}$ Este gancho de carne es inicialmente atribuido a Monte Bernorio por Navarro (Navarro, 1939: Villarén; Sancho, 1975: lám. VIII) e identificado posteriormente como procedente de Cantabrana por Delibes et al. (1999: 105 y fig. 99).
} 
La dificultad técnica sobre la adscripción étnica del grupo humano que habitó Altikogaña es una cuestión que surge al hilo de todo lo anterior y se encona en el asunto sobre el presunto carácter celta de los Várdulos. $\mathrm{Ni}$ tan siquiera nosotros coincidimos en nuestra visión que varía entre la opinión que hace determinante la ausencia de datos decisivos a la hora de poder posicionarse en ese aspecto y el rechazo a una vasconización tardía carente del más mínimo rigor científico. Una propuesta de adscripción étnica se realizó en el estudio inicial del armamento (MARTÍNEZ, 2003: 167) tomando como referencia el trabajo de A. Emborujo (1987) y Santos et al. (1992), quienes proponen adscribir el entorno del valle de Allín, sierra de Urbasa e incluso parte de la Sakana a los várdulos, a partir de las fuentes históricas, la toponimia y la epigrafía, opinión que también comparten Beltrán y Velaza (2013: 63).

Dentro de este orden de cosas, hay que señalar también el grupo de signa equitum conformado por los hallazgos de la necrópolis de Arce-Mirapérez (Miranda de Ebro, Burgos). Abásolo y Ruiz Vélez 1978: 268-269, Lám. 1.5.) (fig. 10.1) y el ejemplar de la necrópolis de Piñuelas, asociada al poblado berón de La Hoya (Laguardia, Álava) (LLANOS, 2002: 126, fig. 10 y foto 10) (fig. 10.2). Ambos presentan una temática similar de dobles prótomos de caballo contrapuestos, de diseño estilizado, sobre soporte o base cónica moldurada. La afinidad en el diseño de la base cónica, el estilo general y el tamaño, permiten hablar de la existencia de otro grupo diferenciado a caballo entre autrigones y berones, aunque geográficamente próximos. Un tercer ejemplar menos conocido se halló en el poblado de La Custodia (Viana, Navarra) (fig. 10.3), identificada con la Vareia de los berones, que comparte con los dos anteriores el mismo esquema compositivo aunque en un estilo ligeramente diferente, con prótomos de caballo mucho más estilizados y base cónica decorada únicamente con dos líneas incisas formando bandas (LABEAGA, 2000: 9293, fig. 210). Este grupo, claramente definido y no muy lejano geográficamente del área que nos ocupa, comparte con el de Altikogaña su reducido tamaño y la simbología general del caballo, mientras que contrasta en el resto de elementos definitorios del tipo. Esto es algo que resulta interesante puesto que abunda en el hecho de que existen algunos tipos concretos que se circunscriben a áreas geográficas (más o menos definidas) a la vez que permite constatar la existencia más general de todo un conjunto de piezas de reducido tamaño que contrastan con los ejemplares de mayor tamaño presentes en las diferentes variedades de tipología celtibérica.

En resumen, todo lo anteriormente expuesto, nos lleva a proponer la existencia de un tipo nuevo tipo de signum equitum que queda definido por los hallazgos de Altikogaña y Monte Bernorio.

\section{SOBRE LA FUNCIÓN DE LOS SIGNA EQUITUM}

Una cuestión de suma importancia es la interpretación de estos signa equitum como objetos funcionales en la compleja sociedad que los elaboró. Así, las diversas hipótesis sobre su cometido son elemento de debate desde hace tiempo, y han estado centradas, principalmente, en los ejemplares del tipo "Numancia ". Estos, interpretados en el sentido de elementos pertenecientes a unas élites prestigiadas, han sido explicados como signa equitum por Almagro-Gorbea (1998: 103-105), Almagro-Gorbea y Torres (1999: 97) y por Lorrio y Graels (2013: 213-214), mientras que son interpretados como báculos de distinción por Jimeno et al. (2004: 163-170) y por Pastor (1998: 39; 2004: 1472) a partir del hallazgo en la Tumba 38 de Numancia de dos ejemplares que te-

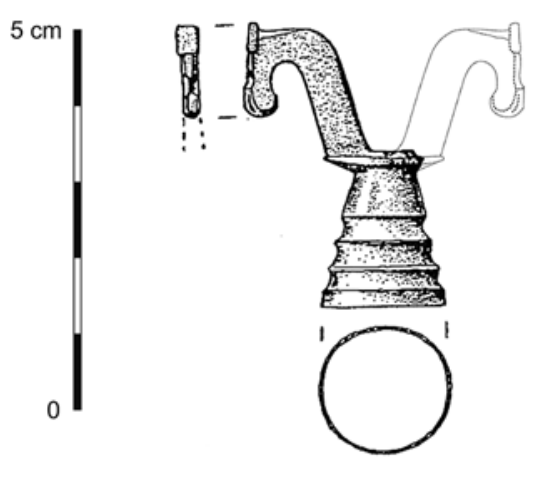

1

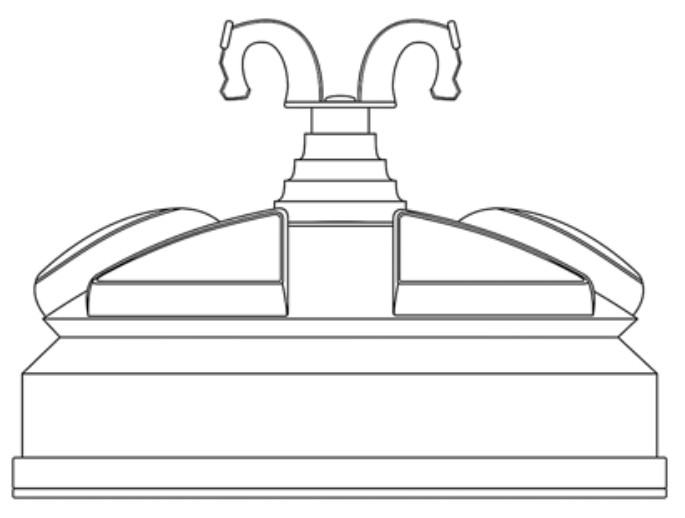

2

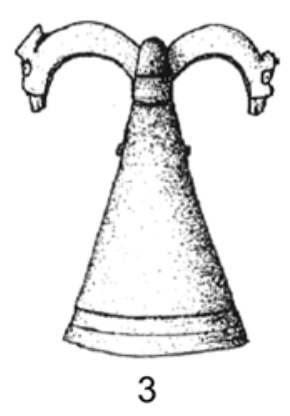

3

Fig. 10. Signa equitum 1. Arce-Mirapérez (Miranda de Ebro, Burgos), según Abásolo y Ruiz Vélez (1978: 268-269, Lám. 1.5.) con prótomo restituido (A.M.V. 2013); 2. representación de la vista lateral del signum equitum (o foculus) de la necrópolis de Pinuelas (Laguardia, Álava) (A.M.V. 2013 a partir de Llanos, 2002: foto 10); 3. La Custodia (Viana, Navarra) (Labeaga, 2000: fig. 210). / Signa equitum: 1. Arce-Mirapérez (Miranda de Ebro, Burgos), according to Abásolo and Ruiz Vélez (1978: 268-269, Lám. 1.5.) with restored protome (A.M.V. 2013); 2. representation of the side view of the signum equitum (or foculus) of the necropolis of Pinuelas (Laguardia, Álava) (A.M.V. 2013 from Llanos, 2002: photo 10); 3. La Custodia (Viana, Navarra) (Labeaga, 2000: fig. 210). 


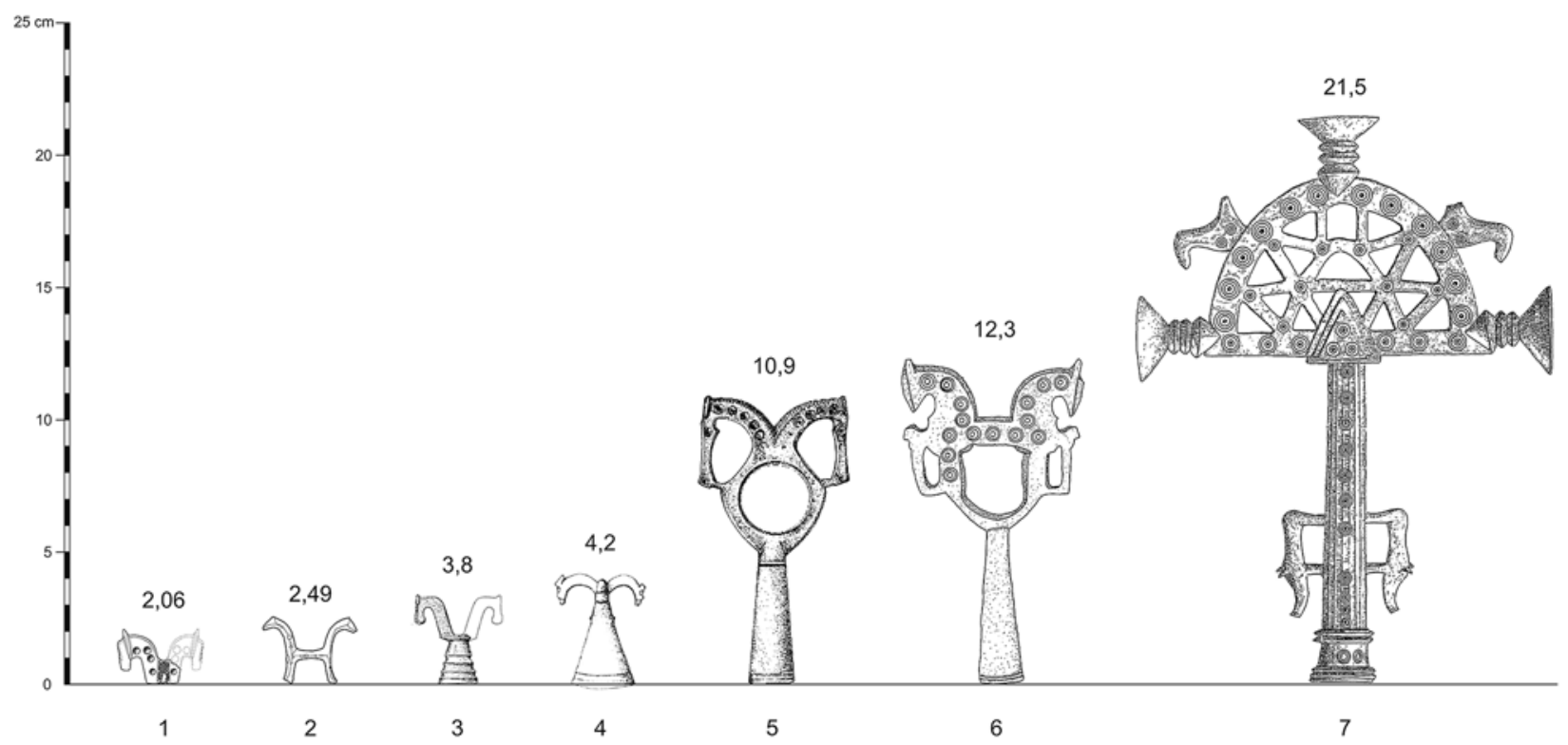

Fig. 11. Comparativa de tamaños entre el ejemplar de Altikogaña y otros citados en texto e identificados como signa equitum (nos 1-7), estandartes (nos 5-7) o báculo ( $n^{\circ}$ 6), según diferentes autores: 1. El Otero (Rueda de Pisuerga, Palencia); 2. Altikogaña (Eraul, Navarra); 3. Arce-Mirapérez (Miranda de Ebro, Burgos); 4. La Custodia (Viana, Navarra); 5. Procedencia desconocida (seguramente celtibérico); 6. Numancia (Garray, Soria); 7. Necrópolis de Miraveche (Miraveche, Burgos). Según A.M.V. (1 y 2), Abásolo y Ruiz Vélez, 1978: Lám. 1.5. (3), Labeaga, 2000: fig. 210 (4); Lorrio y Graels, 2013 : 205 (5); Almagro-Gorbea y Torres, 1999: 227, fig. 31.2 (6) y Schüle, 1969: 146: 2 (7). / Comparison of sizes between the issue of Altikogana and others cited in text and identified as signa equitum (No. 1-7), standards (No. 5-7) or crosier (No. 6), according to different authors: 1. El Otero (Rueda de Pisuerga, Palencia); 2. Altikogaña (Eraul, Navarra); 3. Arce-Mirapérez (Miranda de Ebro, Burgos); 4. La Custodia (Viana, Navarra); 5. Provenance unknown (probably celtiberian); 6. Numancia (Garray, Soria); 7. Necropole of Miraveche (Miraveche, Burgos). According to A.M.V. (1 y 2), Abásolo and Ruiz Vélez, 1978: Lám. 1.5. (3), Labeaga, 2000: fig. 210 (4); Lorrio and Graels, 2013: 205 (5); Almagro-Gorbea and Torres, 1999: 227, fig. 31.2 (6) and Schüle, 1969: 146: 2 (7).

nían asociadas conteras a una distancia aproximada de 1,5 m (JIMENO et al., 2004: 85, fig. 50.1 y 50.2). Argumentando su lectura como estandartes, Lorrio y Graels (2013: 214), nos recuerdan que lo realmente explícito en la Antigüedad era la propia iconografía e igualmente apuestan por el nítido "carácter parlante" de estas piezas, lo cual evidencia su interpretación (ALMAGRO y LORRIO, 2010). Ahora bien, los distintos planos en que pueden ser descifradas estas representaciones de équidos y, sobre todo, el ínfimo tamaño de la pieza aquí presentada en comparación con los ejemplares anteriormente citados (fig. 11), nos hace albergar serias dudas sobre la función de este signum como estandarte y descartamos su interpretación como "distintivo de élite social", es decir, como elemento diferenciador de los componentes de un hipotético grupo jerarquizador del poblado y detentores de los distintos mecanismos de organización. Estos grupos dominantes son comúnmente interpretados como equites.

Recientemente, una propuesta de seriación de las pequeñas piezas de la Cantabria Histórica (MARTíNEZ y FERNÁNDEZ, e.p.) ha ahondado en su dificultad para ser empleadas como estandarte y su más coherente lectura como remates de cetros. Igualmente, descartan su uso como elementos de lujo y mantienen los autores que la adquisición de esos pequeños signa no indicaba el potencial económico de un individuo sino el reconocimiento de su prestigio social.

Con cierto parecido formal, pero con una esquematización notablemente más acentuada que en los ejemplares cántabros arriba citados, el signum de Altikogaña presenta una descuidada ejecución, quizás intencionada, más propia del tratamiento del caballo en el arte esquemático de ese período ${ }^{9}$ que del buen acabado que se aprecia en el resto de bronces de este poblado conservados en el local del Centro de Estudios de Tierra Estella. Es decir, más que la imposibilidad del artesano para un tratamiento más naturalista del caballo, nada difícil por cierto, parece más plausible que pudiera ser intencionada la elaboración del objeto con esta forma esquemática, cuya presencia, trazada de forma perecedera, fuera habitual en los diferentes ritos de paso que ponían en contacto la comunidad con lo sagrado. No es difícil suponer que frente a las escasas representaciones en bronce, la figura esquemática del caballo trazada en otros soportes y materiales (madera, pintura, etc.) fuera habitual a lo largo de las distintas celebraciones del calendario religioso-agrícola del poblado.

Así, nos preguntamos, al igual que Romero et al. (2011) con vacceos y vettones, si este pequeño signum de Altikogaña tuvo el mismo significado para sus poseedores que los de procedencia celtíbera, probable foco

\footnotetext{
${ }^{9}$ Una síntesis de estas imágenes esquematizadas en Royo, 2005.
} 
difusor de estos objetos para el norte del Ebro. En nuestro caso, creemos que no. Tampoco consideramos que su función sea la de báculo de distinción, entendiendo ésta en su sentido más amplio. El insignificante tamaño y el acabado de la pieza, nos lleva a darle un sentido ritual o religioso relacionado con ritos de paso, p.e. de iniciación a un grupo de edad ${ }^{10}$. Además, así como la articulación e ideología de los ritos difieren de un nivel cultural a otro, lo mismo se puede aplicar a ciertas imágenes comunes a distintos espacios geográficos. Tenemos como paradigma el jinete de las monedas celtibéricas e ibéricas, que actúa como un "falso amigo iconográfico". Efectivamente, tomando como referencia esa figura del jinete lancero pesado, armado con kontos, no podemos pasar de su valor como icono prestigioso, tomado del ámbito helenístico, a la realidad táctica de una caballería ligera atestiguada por las fuentes clásicas (QUESADA, 2006: 157-158). La realidad y la imagen tan solo son tangencialmente coincidentes en este caso. En el mismo sentido se puede alegar la mínima representación de esta iconografía en el corpus lapidario de la zona en época romana, que en su primer momento bebería de la tradición indígena y en el que la nobleza local sería uno de los grupos principales demandantes de esa forma de distinción e inspiradores del trabajo de los lapicidas (MARCO, 1979). Lo mismo se puede afirmar, aunque de forma más extensa si el origen de las primeras de estas manifestaciones está en el asentamiento de personal alóctono, militar o civil, y las lápidas no sean un registro válido para establecer hechos indígenas (GARCÍA, 1991).

\section{EL SANTUARIO DEL BALCÓN DE LAZKUA}

\subsection{Localización y descripción}

La más septentrional de las Peñas de Larrion, la de Lazkua (fig. 2), tiene un bonito balcón natural colgado recientemente bautizado como "el mirador de Lazkua". Ubicado en la parte baja de la Peña de Lazkua y unos 10 m elevado del suelo, este balcón recorre la peña de norte a sur dejando amplias terrazas favorecidas por el extraplomado de la roca que crea auténticos covachos naturales (fig. 12). Desde este mirador natural se dispone de una vista privilegiada sobre el valle de Allín, pero también sobre el poblado de Altikogaña, el paso del río Urederra al pie de las Peñas de San Fausto así como sobre Artabia y el paso hacia las sierras de Urbasa y Andia.

Las peñas de Lazkua y Altikogaña únicamente quedan separadas por una estrecha vaguada por la que transcurre el viejo camino de herradura, anteriormente mencionado, que unía la parte norte de Yerri, con el valle de Allín (fig. 3).

La elección del lugar no es casual ya que quien se acerque al lugar percibe rápidamente esa religiosidad inmanente que envuelve a ciertos espacios naturales. El lugar cuenta con unas condiciones geográficas similares a otros espacios sagrados de la protohistoria identificados como santuarios al aire libre (MARCO y ALFAYÉ, 2008; LORRIO y ROYO, 2013; ROYO, 2004: 144). Son lugares sin depósitos arqueológicos ni estructuras apreciables y cuyas manifestaciones cultuales se nos

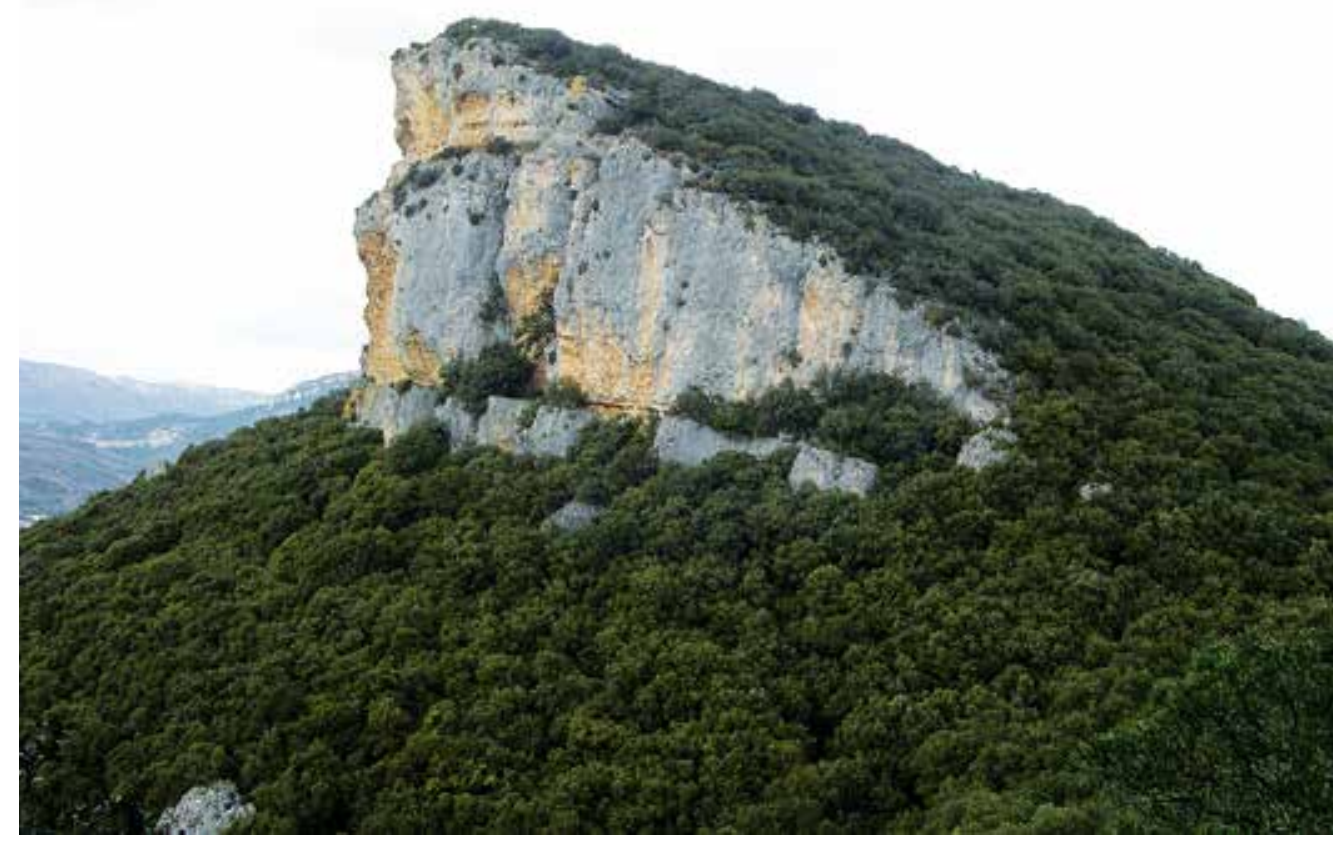

Fig. 12. Peña de Lazkua desde Altikogaña. Al pie de la misma, el Balcón de Lazkua. / Lazkua crag from Altikogana. At the foot of the same, the balcony of Lazkua.

\footnotetext{
${ }^{10}$ En la zona ha perdurado hasta el s. XX un rito en el que se pasa de la infancia a la juventud, lo que permite acceder a sus celebraciones así como poder representar a la casa en los auzolanes o trabajos concejiles (Zufiaurre y Argandoña, 1995).
} 
escapan en su aspecto inmaterial, aunque su uso ritual es deducible por pinturas, grabados o restos epigráficos plasmados en la roca, algo que se da en el Balcón de Lazkua, razón por la cual cabe definir este espacio como un santuario. Ese carácter de espacio sagrado queda remarcado por el acceso que presenta cierta dificultad. Para llegar al balcón hay que pasar por un estrechamiento entre dos rocas y salvar un escalón de dos metros, algo que acentúa el carácter recogido del lugar.

En la segunda mitad del S. XX un religioso del valle "cristianizó" el lugar con una enorme cruz ampliamente visible desde el valle que ha hecho que en el pueblo de Larrión, a quien pertenece el paraje y situado a los pies del cantil, denominen a la peña de Lazkua como la Peña de la Cruz.

\subsection{Los grabados fusiformes}

Al inicio del balcón (fig. 13), por su parte meridional, se encuentra un conjunto de grabados de tipo fusiforme en número total de 12, con trazos alargados y estrechos, bordes con arista y secciones en "V" acusadas (figs. 14 y 15). Todos los grabados se encuentran agrupados en el borde exterior del balcón. 10 de ellos presentan características similares en cuanto a tipometría, profundidad del trazo y pátina, y se distribuyen en tres conjuntos de trazos atendiendo a la orientación que presentan, en número de cuatro, cuatro y dos. A ellos se les suman dos grabados más, de anchura y profundidad menores que los anteriores así como pátina muy superficial, y que presentan orientaciones diferentes a los anteriores. Además se observa el pulimento de la roca madre caliza en

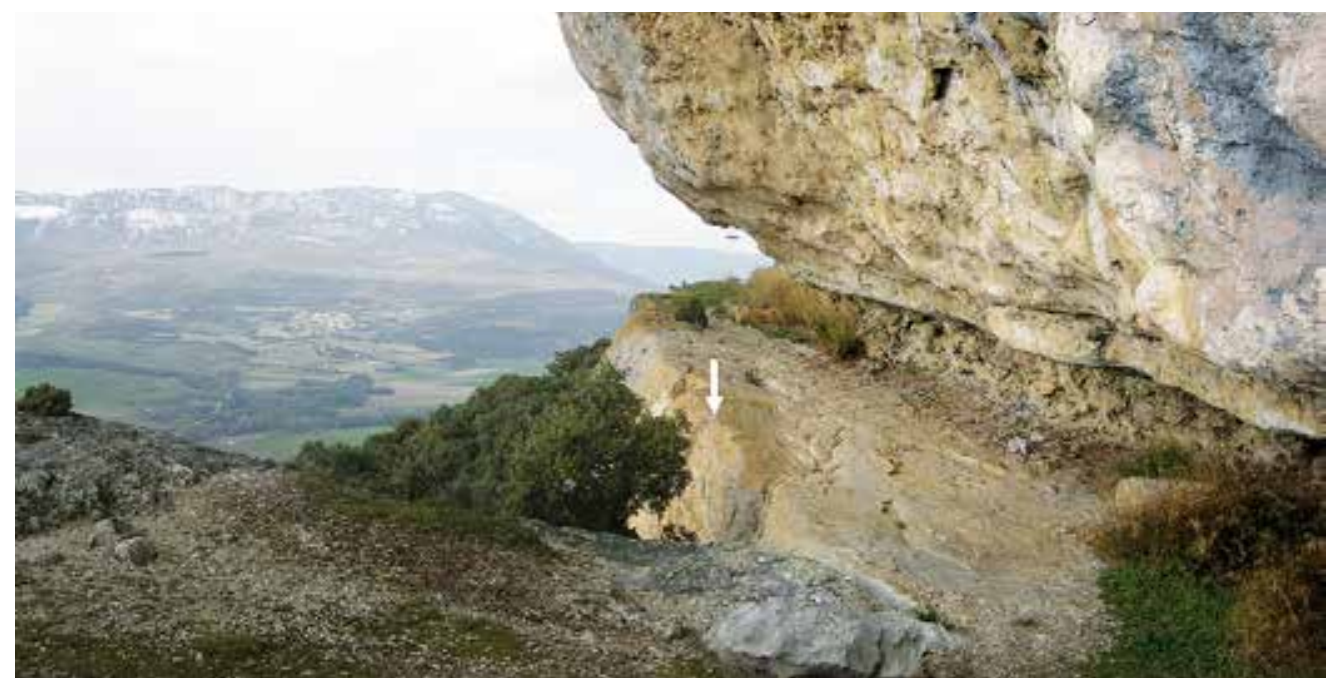

Fig. 13. Balcón de Lazkua. Detalle del inicio y zona donde se ubican los grabados fusiformes. / Lazkua balcony. Detail of the beginning and area where the spindle-shaped engravings are located.
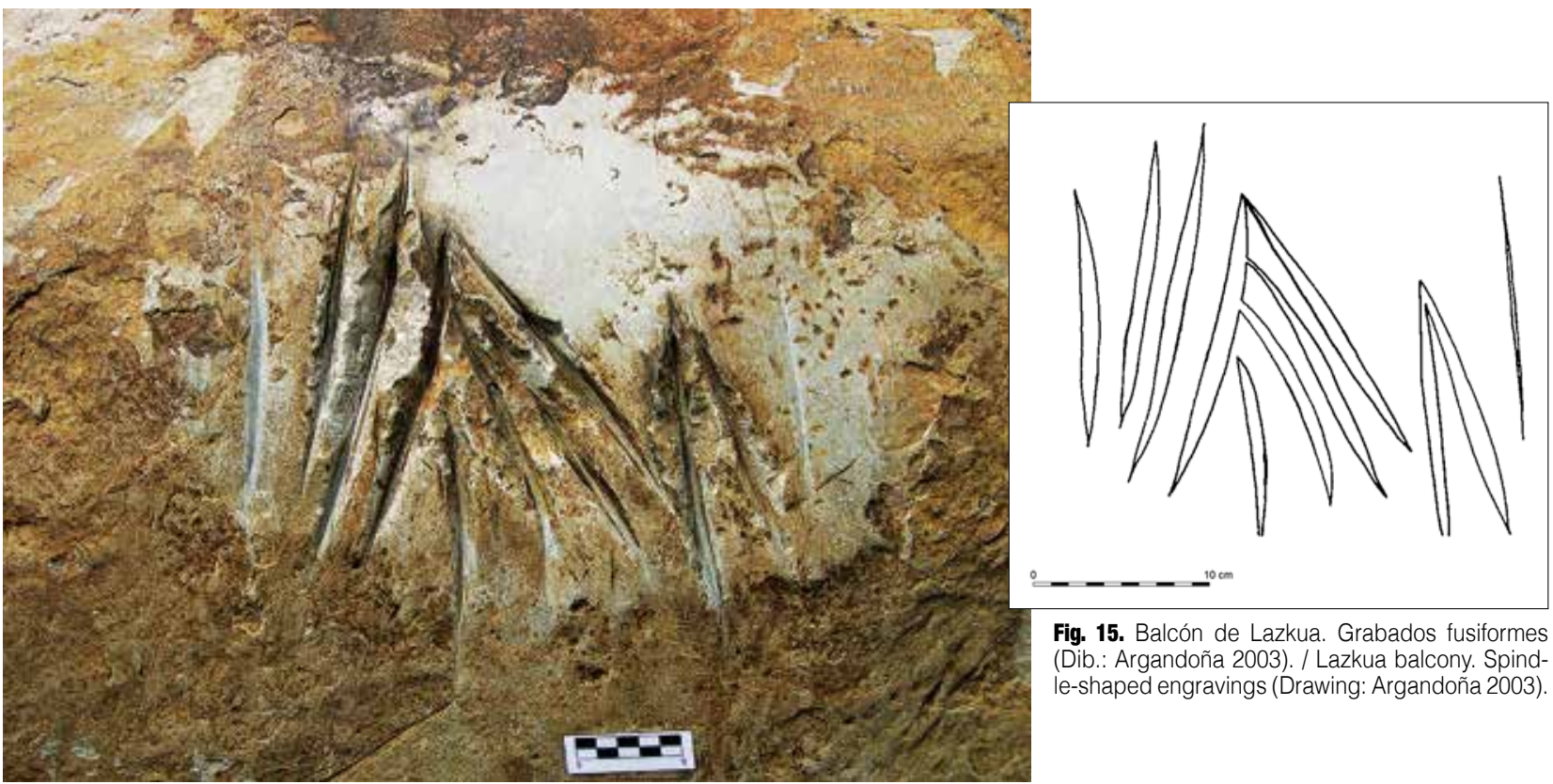

Fig. 15. Balcón de Lazkua. Grabados fusiformes (Dib.: Argandoña 2003). / Lazkua balcony. Spindle-shaped engravings (Drawing: Argandoña 2003).

Fig. 14. Balcón de Lazkua. Grabados fusiformes (Foto A.M.V. 2015). / Lazkua balcony. Spindle-shaped engravings (Photo A.M.V. 2015) 
la misma área que ocupan los grabados y en combinación con estos. En cuanto a la orientación del balcón, mira hacia el oeste. Es posible que la vista del ocaso influyera en su elección, pero lo cierto es que la morfología de las peñas no ofrece ninguna otra posibilidad de hallar espacios similares con orientación diferente.

Este tipo de grabados se identifican frecuentemente con afiladeras y de este modo han quedado fijados en el imaginario popular, de hecho, la tradición local explica los surcos como obra de moros puesto que son "la evidencia del afilado de sus espadas" (LÓPEZ y ARGANDOÑA, 2003). Se ha descartado esta explicación por dos razones principales, una que la roca madre es un tipo de caliza dura y ese tipo de piedra no se emplea para el afilado, y dos, que el tipo de afilado que requiere el filo de los objetos cortantes no deja ese tipo de huella. Es más, atendiendo al tipo de surco y su sección, el grabado responde al modelo de huella derivado del movimiento de vaivén producido durante un movimiento de corte, acción incoherente con el afilado de útiles cortantes.

\subsection{Paralelos y cronología}

Los grabados fusiformes presentan una amplia difusión, una gran variedad de contextos y un amplio abanico cronológico. Pero lo cierto es que también está ampliamente representado durante la Edad del Hierro en numerosas áreas peninsulares (ROYO, 2009) así como en numerosas manifestaciones de la Cerdaña francesa (CAMPMAJÓ y CRABOL, 2009: 384 y 386). Dentro de ellas, por una cierta proximidad, cabe citar la que J. I. Royo denomina "Grupo pirenaico y prepirenaico", para la cual señala, entre sus diferentes manifestaciones características, la presencia de grabados fusiformes ejecutados mediante abrasión (ROYO, 2009: 45-46) como el caso que nos ocupa.

En el caso del Balcón de Lazkua, uno de los elementos determinantes para la atribución cronológica del santuario y sus grabados se encuentra precisamente en su estrecha proximidad a Altikogaña, de hecho, el santuario es perfectamente visible desde Altikogaña (fig. 12). No debemos olvidar, además, la continuidad en el poblamiento durante la Edad del Hierro en estas peñas que viene confirmada por la presencia de un poblado menor de la I. Edad del Hierro en la Peña Bargagorria, al cual sucede Altikogaña (ARMENDÁRIZ, 2010a). A todo ello hay que añadir que el paso natural para que los habitantes del poblado accedieran al valle de Allín es el Puerto de Eraul, que se encuentra precisamente entre Altikogaña y el Balcón de Lazkua (fig. 3). No parece necesario incidir en que existe una vinculación clara entre el poblamiento de la Edad del Hierro en estas peñas con el Balcón de Lazkua. Igualmente detectamos que el grupo militar que ocupó la cima de Altikogaña en época medieval también ocupó este espacio dejando su impronta en forma de entalladuras para bloquear el paso de acceso al Balcón de Lazkua con algún cierre de madera, algo similar a lo que se observa en la entrada de la Peña Roya de Etxauri.

El carácter de santuario, por lo tanto, viene determinado por la combinación de dos elementos: la singularidad del emplazamiento y la religiosidad inmanente que posee, como lo demuestra el hecho de haber quedado fijada en el imaginario popular, junto a la presencia de grabados. Y esta combinación de elementos ha sido precisamente la clave que ha permitido identificar numerosos lugares como santuarios (ROYO, 2004: 144; 2009: 39). En ese orden de cosas, también aquí se da lo que M. Eliade denominó hierofanía (ELIADE, 1970: 64), término que sirve para indicar los casos en que el hombre siente la presencia de lo sagrado en objetos o lugares existentes. Así, suponemos que para el homus religiosus de Altikogaña, el balcón de Lazkua se convierte en algo distinto, en algo sobrenatural.

Un ejemplo interesante de lugar identificado como santuario protohistórico que presenta grabados fusiformes lo tenemos en el Arroyo de Horcajos (Romanos, Zaragoza) con una vigencia también durante la Edad del Hierro (ROYO, 2010: 94-95). Pero quizás el ejemplo más ilustrativo y cercano sea el recientemente identificado en el poblado de Murillo (Mués, Navarra), en el valle de la Berrueza y a unos $18 \mathrm{~km}$ de distancia de Altikogaña y Lazkua11 (fig. 4.16). En la parte superior del poblado y hacia el extremo oeste, mirando hacia el paso de Congosto (figs. 16 y 17), puede verse en un afloramiento de roca destacado en el terreno la presencia en su parte superior de una cazoleta irregular que aún recoge agua, con bordes redondeados y un pequeño canalillo tallado en un extremo que permite que el agua rebose. En el borde de esta cazoleta pueden verse dos grupos diferenciados de cuatro grabados fusiformes cada uno (fig. 18). Este lugar combina también varios elementos que nos aproximan al Balcón de Lazkua: presencia de grabados fusiformes, afloramiento natural destacado, con vistas sobre un paso estratégico y ubicación al interior de un poblado fechado en la II. Edad del Hierro.

Un último lugar a señalar, precisamente porque combina los grabados con el agua, es el estanque celtibérico de La Barbacana (Laguardia, Álava) (LLANOS, 2010). En los escalones de este estanque se observan varios grabados que Llanos identifica con huellas de afilado de objetos de corte (LLANOS, 2010: 270 y fig. 14) y que tipológicamente pueden asimilarse al tipo fusiforme aunque con perfiles menos acusados. El estanque debió estar en uso ya durante los ss. III y II a.e. y es posible

\footnotetext{
${ }^{11}$ El santuario se ha identificado recientemente por lo que no cuenta con el estudio correspondiente. Debido a sus características constituye un paralelo ilustrativo por lo que se ha decidido finalmente incluir estas referencias, las primeras que se publican. Sobre el poblado como tal, Armendáriz, 2008: $n^{\circ} 222$.
} 


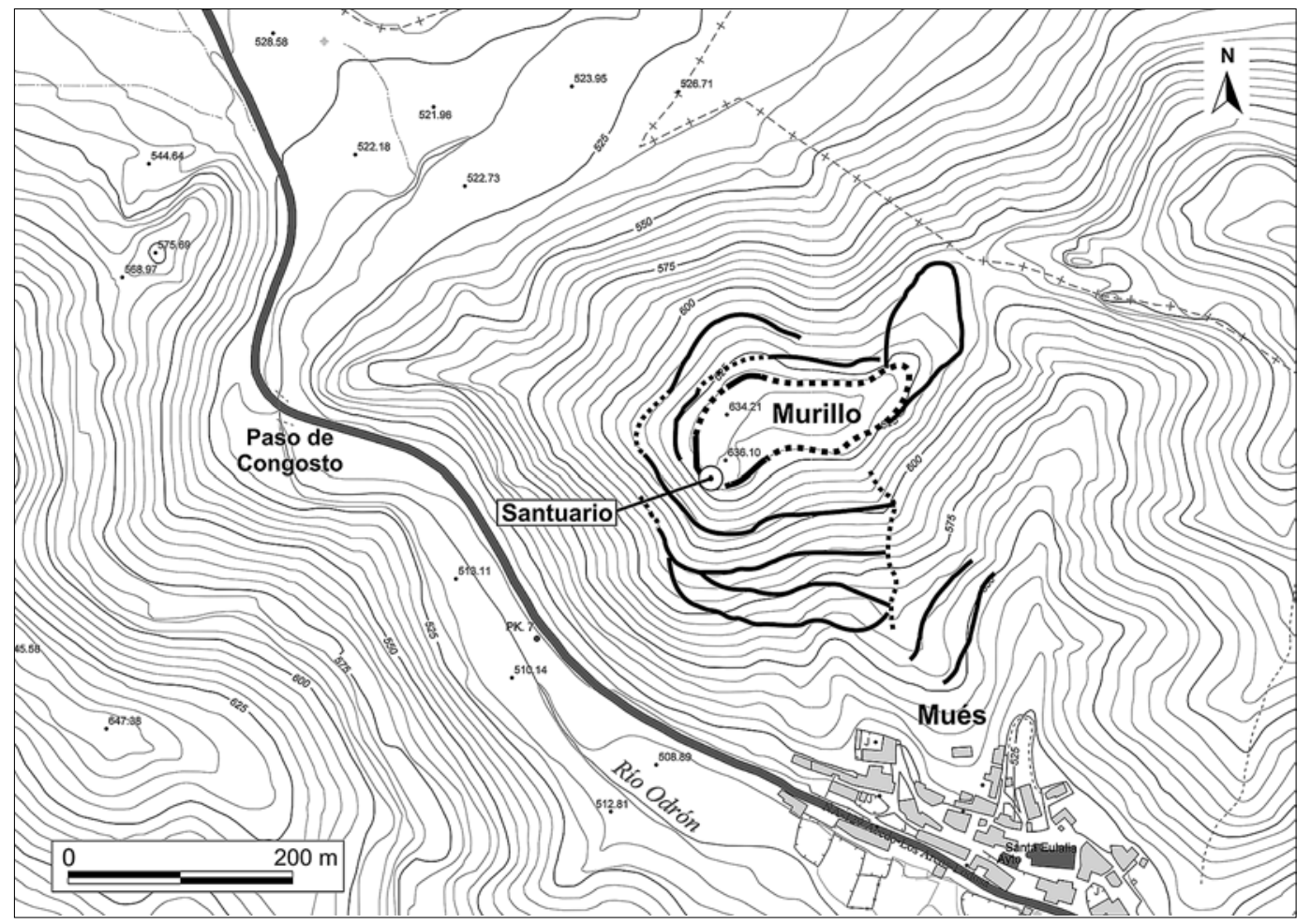

Fig. 16. Murillo (Mués). Croquis del poblado a partir de Armendáriz (2008: $\left.\mathrm{n}^{\circ} 222\right)$ y ubicación del santuario. / Murillo (Mués).Sketch of the village from Armendariz (2008: $\left.\mathrm{n}^{\circ} 222\right)$ and location of the sanctuary.

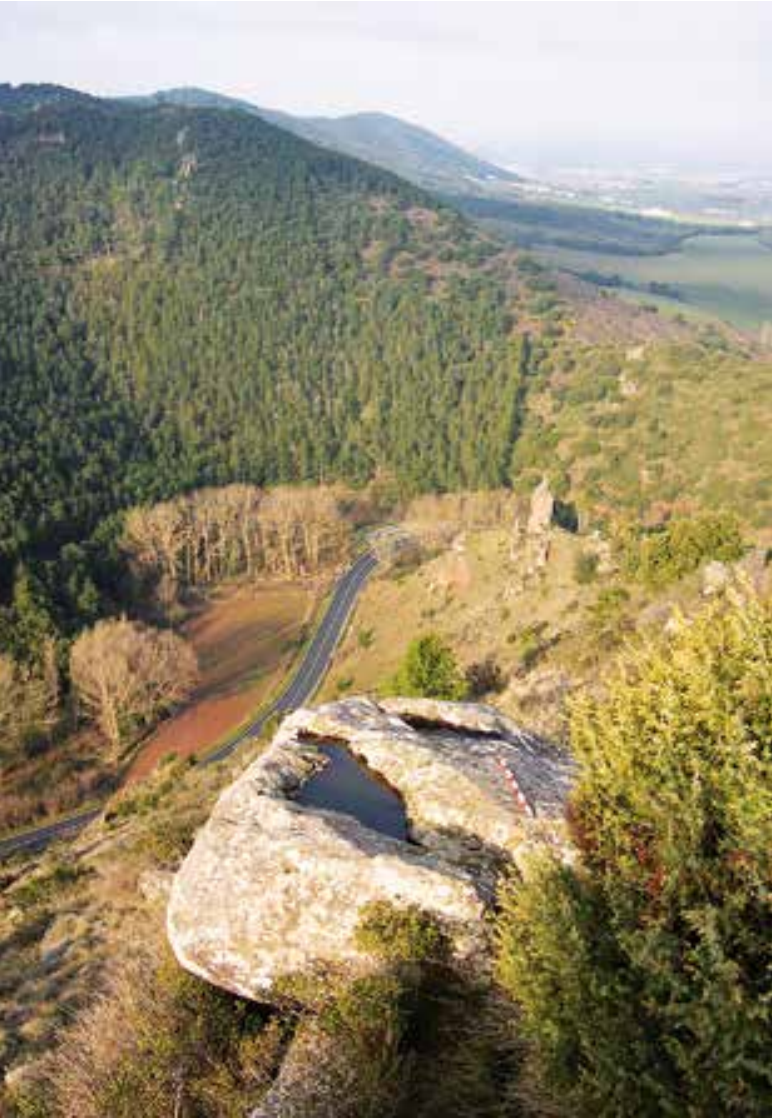

Fig. 17. Vista general del área del santuario del poblado de Murillo, dominando el paso de Congosto a sus pies. / General view of the area of the sanctuary of the village of Murillo, dominating the Congosto pass at his feet.

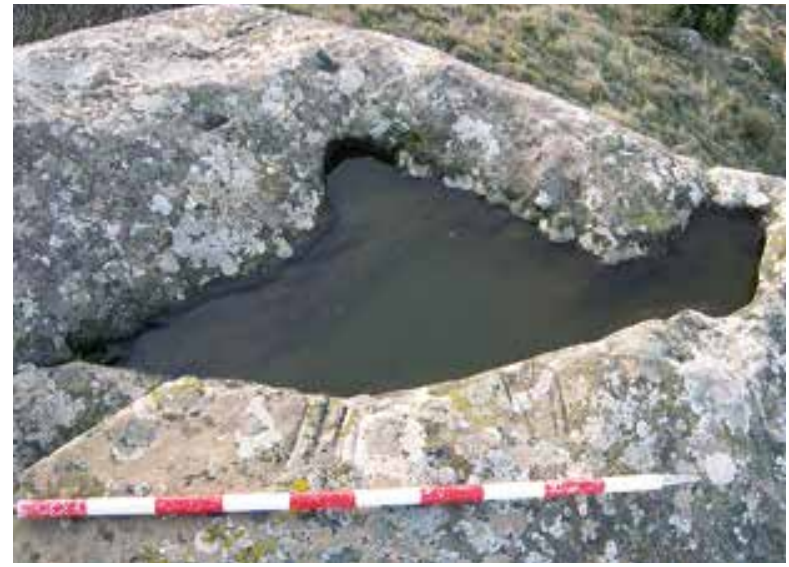

Fig. 18. Detalle de conjunto de la cubeta con agua y grabados fusiformes a borde de la misma. / Set detail of the bucket with water and spindle-shaped engravings on the edge of the same.

que continuara su vida útil en fechas posteriores. A esta función utilitaria también se le suma una función ritual que vendría atestiguada, precisamente, por los grabados (LLANOS, 2010: 79-80).

\subsection{El Balcón de Lazkua y los santuarios proto- históricos en Navarra}

El santuario del Balcón de Lazkua, y junto a él el de Murillo, pasan a incorporarse al catálogo de lugares identificados hasta la fecha como santuarios en Navarra, ciertamente reducido y variado. 
A día de hoy, los lugares identificados en Navarra como santuarios han sido tres: la Peña del Cuarto (Learza, Etayo) (MONREAL, 1977: 113-126), Peña Roya (San Kiriako, Echauri) (NUIN, 1994: 125; ARMENDÁRIZ, 2008: $n^{\circ} 41$ ) y San Quiriaco (Garisoain, Gesalaz) (JIMENO, 1975; ARMENDÁRIZ, 2008: $\left.n^{\circ} 166\right)$. La Peña del Cuarto es un lugar que encaja en el modelo descrito anteriormente puesto que se trata de un afloramiento de arenisca muy destacado en el entorno, con un espacio a medio camino entre el abrigo y el covacho y en el cual se hallan grabados varios équidos estilizados mediante línea incisa, todo ello, temática y estilo filiforme, típico de la Edad del Hierro.

La identificación de Peña Roya como santuario resulta algo más problemática. Se trata de una peña en un lugar destacado de la sierra de Sarvil donde se han tallado unos escalones y se observan algunas oquedades identificadas como cazoletas así como acanaladuras (NUIN, 1994: 125). Esos escalones pueden llevarnos en primera instancia a ponerlos en relación con estructuras como el conocido altar rupestre de Ulaca (Solosancho, Ávila) (ÁLVAREZ SANCHís et al. 2008: 345-346; FABIÁN, 2010: 244-246), pero lo cierto es que son muy diferentes. Mientras que en Ulaca se trata de unos escalones frontales tallados en un afloramiento de granito exento que dan acceso a una plataforma, en el contexto del interior de uno de los grandes oppida de los vettones, en Peña Roya se trata de unos escalones adosados de forma lateral a la roca en un lugar escarpado y de reducidas dimensiones que forma parte de un recinto semirrupestre. Es más, los paralelos conocidos en Navarra y áreas próximas para los escalones nos remiten directamente al mundo altomedieval o medieval, donde la ocupación con carácter militar de pequeños espacios de amplia visibilidad y difícil acceso es frecuente. Y así por ejemplo encontramos escalones tallados en los castillos de Gazteleko Haitza (Urdiain, Navarra) (SAGREDO, 2006: 309-312), La Peña Grande (Salinas de Oro, Navarra) (SAGREDO, 2006: 400-402), Toro (Toro, Navarra) (SAGREDO, 2006: 245-248), Ausa-Gaztelu (Zaldibia, Gipuzkoa), Jentilbaratza (Ataun, Gipuzkoa) y Marquínez (Araba) (RAMOS, 2000: 511 y 514). De hecho, el supuesto altar de Peña Roya no resulta para nosotros más que una parte del antepecho labrado en la roca que recorre todo el reborde norte de la plataforma rocosa, su parte más accesible. Concretamente, el ventajoso lugar desde el que hostigar el intento de forzar la puerta del recinto cuyo pasadizo de acceso se encuentra a los pies del "altar". Algo similar lo encontramos en los recintos mencionados en los que la reutilización de elementos naturales es una constante, produciendo abigarrados conjuntos en los que prima la adaptación al lugar. Lo que nos lleva a pensar en un uso medieval defensivo y descartar su uso ritual o de santuario en base a los elementos mencionados, ya que los evidentes trabajos de acondicionamiento del lugar coinciden con la adaptación al terreno de otros recintos medievales. Ese carácter militar del lugar estaría relacionado con la presencia en Etxauri, durante el siglo XI, de una de las "tenencias" de la monarquía pamplonesa (PESCADOR, 1999: 131, 139 y 143).

Se ha identificado San Quiriaco (Garisoain, Gesalaz) como santuario a partir del hallazgo de una ara reutilizada en la ermita y dedicada por Domitius MarceIlus (JIMENO, 1975), entendiendo con ello que la misma continuaba con una tradición ritual o religiosa del lugar cuyo origen se situaría en momentos precedentes a la romanización. En este lugar se han hallado materiales que ocupan un arco cronológico que se extiende desde el Bronce Final hasta el Alto Imperio, lo que unido al hecho de carecer de defensas y no encajar en un modelo determinado de poblamiento, llevan a Armendáriz a plantear que este lugar estuvo destinado al culto, quizás en relación con el poblado fortificado de Murumendi (Alloz, Yerri) (ARMENDÁRIZ, 2008: n 169).

\section{EL SIGNUM EQUITUM Y EL SANTUARIO. CON- CLUSIONES}

La religiosidad y la ideología impregnan el día a día de la vida en la Edad del Hierro y son elementos esenciales de la identidad de las personas y de los pueblos en la antigüedad. Aspectos que no resultan sencillos de rastrear desde la arqueología puesto que no siempre dejan evidencias materiales. Por eso, la identificación de cualquier nuevo elemento que nos informe sobre ambos mundos resulta sumamente valiosa. En este caso se presentan dos novedades, un signum equitum y un santuario, que tienen como eje común su vinculación con el poblado fortificado de Altikogaña.

El signum es una pequeña figura de bronce con una composición a base de dos mitades delanteras de caballo unidas de forma simétrica. Este esquema básico encierra una simbología común a otros objetos identificados como signa equitum. Las características formales permiten a su vez identificarlo como un nuevo modelo tipológico. El esquematismo y el reducido tamaño, por su parte, nos remite a un uso quizás como remate de un cetro, quizás con un sentido simbólico y un uso ritual más que un elemento de clase o de capacidad económica. La cronología del mismo, a partir de los datos proporcionados por Altikogaña y los paralelos tipológicos, cabe proponerla entre finales del s. II a.e. y el final del poblado tras el ataque y destrucción del mismo por parte de tropas romanas, a mediados del s. I. a.e. La ausencia de un contexto estratigráfico en el hallazgo del signum nos lleva a una cierta opacidad en su análisis ya que la polémica interpretativa también se traslada a las piezas contextualizadas. En el caso de esta pieza, creemos conveniente relacionarla con un complejo mundo ritual en el que este signum y el santuario no marcan un destino sino un nuevo eslabón en el que estas manifestaciones se nos presentan más coherentes con el ideario que presuponemos para estas gentes que la presencia de deidades fuertemente marcadas. 
El santuario del Balcón de Lazkua, por su parte, resulta un hallazgo novedoso, por la identificación en sí misma y por el conjunto de características que presenta. Una característica de la religiosidad de la Hispania Indoeuropea es la elección como lugares sagrados y de culto ciertos espacios naturales en los que se percibe o se identifica una religiosidad inmanente por sus características (ALFAYÉ, 2010: 313-315; SEOANE-VEIGA et al., 2013: 20). Es el espacio natural el que posee la sacralidad en primera instancia, y luego son el culto y el rito los que se le incorporan. La identificación de estos santuarios al aire libre no siempre es posible puesto que es frecuente que no dejen ninguna evidencia material que lo permita (TORRES-MARTÍNEZ, 2011: 450451; SEOANE-VEIGA et al., 2013: 21-22) tampoco parece haber un patrón único en la elección de un espacio sagrado pero el carácter sacro de peñas o montes es recurrente en el ámbito religioso de la Edad del Hierro (ALFAYÉ, 2009: 25-26; TORRES-MARTÍNEZ, 2011: 448449).

Una vía que se ha ensayado es la identificación de estos santuarios a través de la combinación de las características del espacio natural con la presencia de grabados, pinturas u otros elementos (SEOANE-VEIGA et al., 2013: 23-24) como por ejemplo en Peñalba de Villastar (Teruel) (ALFAYÉ, 2009: 89-123, 419-422) o en A Ferradura (Amoeiro, Ourense) (GARCÍA QUINTELA y SANTOS, 2008).

El Balcón de Lazkua reúne estas características. Se trata de un mirador natural orientado a poniente, en un cortado de roca, que cuenta con amplias vistas sobre el valle. Al inicio del mismo, en el borde del balcón, se observa un conjunto de grabados fusiformes que constituye la huella material de su uso como santuario al aire libre. El Balcón de Lazkua, por lo tanto, sería un nemeton, un santuario al aire libre, un lugar donde una deidad reside o se manifiesta, y en el que es posible comunicarse con ella (MARCO, 1993; SEOANE-VEIGA et al., 2013: 20; ALFAYÉ, 2005: 229). Muy posiblemente ese carácter sacro cuente además con unos antecedentes históricos a juzgar por el hallazgo de restos de la prehistoria reciente en los alrededores (CASTIELLA, 1986: 146).

A todo ello hay que unirle el hecho de que el Balcón de Lazkua se encuentra inmediatamente al lado de Altikogaña por lo que su vinculación con un poblado en concreto es clara.

Este conjunto de características, la identificación clara del santuario y su vinculación con un poblado concreto, se repiten en Murillo, lo que convierte a ambos en dos identificaciones novedosas en el contexto de Navarra, coherentes a su vez con lo conocido para otros santuarios de la península. Todo ello, unido a la identificación de un nuevo signum equitum, permite abrir nuevas vías al estudio de la simbología y la religión de la Edad del Hierro.

\section{BIBLIOGRAFIA}

\section{ABASOLO, J.A. \& RUIZ VELEZ, I.}

1978 La necrópolis de Miranda de Ebro. Materiales para su estudio. Estudios de Arqueología Alavesa 9, 265-272.

\section{ALFAYÉ VILLA, S.}

2005 "Santuarios celtibéricos", en A. Jimeno (ed.), Celtíberos. Tras la estela de Numancia. 229-234. Soria.

2009 Santuarios y rituales en la Hispania Céltica. BAR International Series, 1963. Oxford.

2010 "Contexts of cult in Hispania Celtica". Cult in context: Reconsidering ritual archaeology. 313-320. Oxford.

\section{ALMAGRO-GORBEA M}

1998 Signa equitum de la Hispania céltica. Complutum 9, 101-115.

\section{ALMAGRO-GORBEA M. \& LORRIO A.}

2010 EL Heros Ktistes y los símbolos de poder en la Hispania prerromana, en Burillo, F. (ed.): VI Simposio sobre celtíberos: Ritos y Mitos. Zaragoza, 157-183.

\section{ALMAGRO-GORBEA M. \& TORRES, M.}

1999 Las fíbulas de jinete y de caballito. Aproximación a las elites ecuestres y su expansión en la Hispania céltica. Zaragoza.

ÁlVAREZ, J. R., MARÍN, C., FALQUINA, A. \& RUIZ ZAPATERO, G.

2008 El oppidum vettón de Ulaca y su necrópolis. Zona Arqueológica 12, 338-363.

\section{ARMENDÁRIZ MARTIJA, J.}

2008 De Aldeas a Ciudades. El poblamiento durante el primer milenio a. C. en Navarra. Colección Trabajos de Arqueología de Navarra, Monografías Arqueológicas 2. Pamplona.

2010a El contexto histórico del castro de la Peña de Bardagorría y el oppidum de Altikogaña (Eraul. Yerri). Cuadernos de Arqueología de la Universidad de Navarra 18, 93-114.

2010b El sitio arqueológico de Amescoazarra (Améscoa Baja). Terra Stellae 1, 78-85.

2011 Completando el mapa de la Edad del Hierro en Tierra Estella. Castros inéditos en las Sierras de Urbasa y Andía. Terra Stellae 3, 96-113.

BELTRÁN, A. \& VELAZA, J.

2013 El límite occidental del convento jurídico cesaraugustano. Cuadernos de Arqueología de la Universidad de Navarra 21, 51-71.

\section{CAMPMAJÓ, P. \& CABROL, D.}

2009 Les grattages naviformes ont-ils des origines ibères? Questions sur leur signification. Acta Palaeohispanica X. Palaeohispánica 9: 381-412. 
CAPRILE, P.

1986 Estudios de los objetos de adorno del Bronce final y Edad del Hierro en la provincia de Álava. Estudios de Arqueología Alavesa, 14. Vitoria-Gasteiz.

\section{CASTIELLA RODRÍGUEZ, A.}

1986 Nuevos yacimientos protohistóricos en Navarra. Trabajos de Arqueología Navarra 5, 133-173.

1989 Monedas prerromanas en Navarra. XIX. Congreso Nacional de Arqueología. 675-682. Zaragoza.

\section{CASTIELLA, A. \& SESMA, J.}

1989 Piezas metálicas de la protohistoria navarra: Armas. Zephyrus XLI-XLII, 383-404.

DELIBES DE CASTRO, G., FERNÁNDEZ MANZANO, J., FONTANEDA, E. \& ROVIRA, S.

1999 Metalurgia de la Edad del Bronce en el piedemonte meridional de la Cordillera Cantábrica. La Colección Fontaneda. Arqueología en Castilla y León. Monografías 3. Zamora.

ELIADE, M.

1970 Tratado de historia de las religiones. Vol. I. Cristiandad. Madrid.

\section{EMBORUJO SALGADO, A.}

1987 El límite entre várdulos y vascones: una cuestión abierta", en Actas del Primer Congreso General de Historia de Navarra, 2. Comunicaciones. Archivística, Prehistoria, Edad Antigua. 379-393. Gobierno de Navarra. Pamplona.

ERICE LACABE, R.

1995 Las fábulas del nordeste de la Península Ibérica: siglos I. a.e. al IV d.e. Institución Fernando el Católico. Zaragoza.

FABIÁN GARCÍA, J. F.

2010 Altares rupestres, peñas sacras y rocas con cazoletas. Ocho nuevos casos abulenses y uno salmantino para la estadística, el debate y la reflexión. Madrider Mitteilungen 51, 222-268.

\section{FERNÁNDEZ, P. A. \& BOLADO, R.}

2011 El recinto campamental romano de Santa Marina (Valdeolea, Cantabria): un posible escenario de las Guerras Cántabras. Resultados preliminares de la campaña de 2009. Munibe Antropologiaa-Arkeologia 62, 303-339.

\section{GARCÍA ARIZA J.}

1991 Estelas decoradas de Aguilar de Codés. Onomástica y tipología indoeuropea. Cuadernos de Etnografía y Etnología de Navarra 28, 208-223.

GARCÍA QUINTELA, M.V. \& SANTOS, M.

2008 "Los "santuarios" de Galicia en la Edad del Hierro: "A Ferradura" (Amoeiro, Ourense) como ejemplo", en Dupré, X., Ribichini, S. y Verger, S. (eds.). Saturna Tellus. Definizioni dello spazio consacrato in ambiente etrusco, itálico, fenicio-púnico, ibérico e celtico. 527-545. Roma.
JIMENO JURÍO, J. M.

1975 Dos aras romanas en Garísoain (Guesálaz). Príncipe de Viana XXXVI, 111-112.

JIMENO JURIO, J. M. (dir.)

1995 Nafarroako Toponimia eta Mapagintza, XXVI. Abárzuza, Lezáiun, Yerri. Iruña-Pamplona.

JIMENO, A., DE LA TORRE, J. I., BERZOSA, R. \& MARTíNEZ, J. P.

2004 La Necrópolis celtibérica de Numancia. Memorias de Arqueología en Castilla y León 12. Salamanca.

LABEAGA MENDIOLA, J. C.,

2000 La Custodia, Viana, Vareia de los Berones. Trabajos de Arqueología Navarra, 14. Pamplona.

\section{LAPUENTE MARTÍNEZ, L.}

1990 Las Améscoas, Estudio histórico-etnográfico. Aristubeltza.

\section{LLANOS ORTIZ DE LANDALUCE, A.}

2002 Las élites de caballería de la Edad del Hierro, en Álava y zonas limítrofes. Estudios de Arqueología Alavesa 19, 108-130.

2010 El estanque celtibérico de la Barbacana (Laguardia, Álava) dentro del conjunto de estanques de la península. Cuadernos de Arqueología de la Universidad de Navarra 18, 263-282.

\section{LÓPEZ, R. \& ARGANDOÑA, P.}

2003 A propósito de las peñas del valle de Allín. Kobie Antropología Cultural 10, 109-116.

LORRIO, A. J.

2010 Los signa equitum celtibéricos: origen y evolución. Palaeohispanica 10, 427-446.

LORRIO A. J. \& GRAELLS, R.

2013 Nuevo signum equitum celtibérico. Boletín del Seminario de Estudios de Arte y Arqueología LXXVII-LXXVIII, 203-218.

LORRIO A. J. \& ROYO J. I.

2013 El guerrero celtibérico de Mosqueruela Teruel: una pintura rupestre excepcional de la Edad del Hierro en el Alto Maestrazgo turolense. Antiqvitas 25, 85-107.

\section{MARCO SIMÓN, F.}

1979 Las estelas decoradas de época romana en Navarra. Trabajos de arqueología navarra 1, 205-250.

1993 "Nemedus Augustus", en Adiego, I.J., Siles, J., Velaza, J.J. (eds.), Studia palaeohispanica et indogermanica J. Untermann. 165-177. Barcelona.

MARCO F. \& ALFAYÉ. S

2008 El santuario de Peñalba de Villastar (Teruel) y la romanización religiosa en la Hispania indoeuropea. Saturnia Tellus. Definizione dello espacio consacrato in ambiente etrusco, itálico, fenicio-punico, ibérico e celtico. 507526. Roma. 


\section{MARTÍNEZ VELASCO, A.}

2003 Altikogaña (Eraul. Navarra) y la conquista romana de los pueblos del extremo oriental del Cantábrico. Revista Española de Historia Militar 40, 163-167.

2009a Monedas del puesto militar romano de Allide (Ibiriku. Navarra)". XIII. Congreso Nacional de Numismática. 495-509. Cádiz.

2009b El puesto militar romano de Allide. Prospección 2008. Kobie Paleoantropología 28, 233-246.

2009c Campamentos romanos de campaña en el extremo oriental cantábrico, en Morillo, A., Hanel, N. \& Martín, E. (eds.). Limes XX. Estudios sobre la frontera romana/Roman Frontiers Studies. Vol. I. Anejos de Gladius. 365-374. Madrid.

\section{MARTÍNEZ VELASCO, A. \& FERNÁNDEZ AGÜERO, L.}

e.p. El signum equitum de El Otero (Rueda de Pisuerga, Palencia) y los signa equitum de la Cantabria Histórica. Complutum. Madrid.

MONREAL JIMENO, A.

1977 Carta arqueológica del Señorío de Learza (Navarra). Pamplona.

MORO, R.

1891 Exploraciones Arqueológicas. Monte Cildá. Monte Bernorio. Loncejares. Arconada. Boletín de la Real Academia de la Historia XVIII, 427-440.

\section{NAVARRO GARCÍA, R.}

1939 Catálogo Monumental de la Provincia de Palencia. Fasc. III. Partidos de Cervera del Río Pisuerga y Saldaña. Diputación Provincial de Palencia. Palencia.

\section{NUIN CABELLO, J.}

1994 La ocupación prehistórica en el Valle de Etxauri (Navarra). Un estado de la cuestión y nuevas aportaciones. Eusko Ikaskuntza, Cuadernos de Sección. Prehistoria y Arqueología 5, 113-140.

\section{PERALTA LABRADOR, E.}

2003 Los cántabros antes de Roma. Bibliotheca Archaeologica Hispana 5. Real Academia de la Historia. Madrid.

2008 La conquista romana de la montaña palentina: el asedio de La Loma (Santibáñez de la Pena). Colección de Historia Montana Palentina 2, 9-36.

\section{PESCADOR MEDRANO, A.}

1999 Tenentes y tenencias del Reino de Pamplona en Álava, Vizcaya, Guipúzcoa, La Rioja y Castilla (1004-1076). Vasconia 29, 107-144.

PÓO, M., SERNA, M. L. \& MARTíNEZ, A.

2010 La Espina del Gallego". En M. L. Serna, A. Martínez y V. Fernández Acebo (coords.): Castros y Castra en Cantabria. Fortificaciones desde los orígenes de la Edad del Hierro a las guerras con Roma. Catálogo, revisión y puesta al día. Acanto. Santander: 283-303.

\section{QUESADA SANZ, F.}

2006 Los celtíberos y la guerra: tácticas, cuerpos, efectivos y bajas. Un análisis a partir de la campaña del 153, en Burillo, F. (ed.): Segeda y su contexto histórico. Entre Catón y Nobilior. 149-167. Zaragoza.

SCHÜLE, W.

1969 Die Meseta-Kulturen der Iberischen Halbinsel. Text und Kataloge. Mediterrane und Eurasische elemente in Früheisenzeitlichen Kulturen Südwesteuropas. Deutsches Archäologisches Institut Abteilung. Walter de Gruyter \& Co. Berlin.

RAMOS AGUIRRE, M.

2000 La frontera occidental del reino de Navarra en 1200. La perspectiva arqueológica. Revista Internacional de Estudios Vascos 45(2), 495-538.

RENOUX, G.

2010 Les Archers de César. Recherches historiques, archéologiques et paléométallurgiques sur les archers dans l'armée romaine et leur armement de César à Trajan. Tome 1. Tesis Doctoral. Université de Toulouse-Le Mirail (IUF).

ROYO GUILLÉN, J. I.

2004 Arte Rupestre de Época Ibérica: Grabados con representaciones ecuestres. Sèrie de Prehistòria i Arqueologia. Servei d'Investigacions Ar $\neg$ queologiques i Prehistòriques. Diputación de Castellón. Castellón.

2009 El arte rupestre de la Edad del Hierro en la Península Ibérica y su problemática: aproximación a sus tipos, contexto cronológico y significación. Saldvie 9, 37-69.

2010 Las rocas grabadas del Arroyo del Horcajo (Romanos, Zaragoza): un nuevo santuario rupestre prehistórico y protohistórico en el Sistema Ibérico. Cuadernos de Arte Rupestre 5, 63-98.

ROMERO F., SANZ, C., DE PABLO, R. \& GÓRRIZ, C.

2011 A propósito de un báculo de Pintia y otros ejemplares vacceos. Vaccea 4, 68-74.

SAGREDO SAN EUSTAQUIO, I.

2006 Navarra. Castillos que defendieron el reino. Tomo I. De Laguardia a Foix, y del Moncayo al Goierri. Pamplona.

SANCHO CAMPO, A.

1937 Palencia histórico monumental: discurso de ingreso como Académico. Publicaciones de la Institución Tello Téllez de Meneses 36, 213-273.

SANTOS, J., EMBORUJO, A. y ORTIZ DE URBINA, E.

1993 Reconstrucción paleogeográfica de autrigones, caristios y várdulos, en Almagro-Gorbea, M. y Ruiz Zapatero, G. (eds.). Paleoetnografía de la Península Ibérica. Complutum 2-3, 449-467.

\section{TORRES-MARTÍNEZ, J. F.}

2011 El cantábrico en la Edad del Hierro. Medioambiente, economía, territorio y sociedad. Bibliotheca Archaeologica Hispana 35. Real Academia de la Historia. Madrid. 
TORRES-MARTíNEZ, J. F., MARTíNEZ VELASCO, A. \& DE LUIS, D.

2012 El Oppidum de Monte Bernorio. Nueve siglos de Historia. Kobie 30, 137-146.

TORRES-MARTÍNEZ, J. F., MARTÍNEZ VELASCO, A. \& PÉREZ FARRACES, C

2012 Augustan campaigns in the initial phase of the Cantabrian war and roman artillery projectiles from the Monte Bernorio oppidum (Villarén, Palencia)". Archaeologisches Korrespondenzblatt 42 (4), 525-542.

2013 Los proyectiles de artillería romana en el oppidum de Monte Bernorio (Villarén, Palencia) y las campañas de Augusto en la primera fase de la Guerra Cantábrica. Gladius XXXIII, 57-80.
TORRES-MARTíNEZ, J. F., MARTÍNEZ VELASCO, A. \& SERNA, M. L.

2013 El oppidum de Monte Bernorio (Villarén, Palencia). Una ciudad fortificada de la Edad Del Hierro en la Montaña Palentina. Colección de Historia de la Montaña Palentina $7,11-86$

VÖLLING, T.

1990 Funditores in römischen Heer. Saalburg Jahrbuch 45, 24-58.

ZUFIAURRE, J. \& ARGANDOÑA, P.

1995 La Gogona, La Gona o el Sundede. Cuadernos de sección. Antropología-Etnografía 13, 287-315. 